\title{
Consensus computational network analysis for identifying candidate outer membrane proteins from Borrelia spirochetes
}

\author{
Melisha R. Kenedy', Edgar J. Scott II', Binu Shrestha' ${ }^{1}$, Arvind Anand², Henna lqbal', Justin D. Radolf 2,3,4,5,6,
} David W. Dyer ${ }^{1}$ and Darrin R. Akins ${ }^{1 *}$

\begin{abstract}
Background: Similar to Gram-negative organisms, Borrelia spirochetes are dual-membrane organisms with both an inner and outer membrane. Although the outer membrane contains integral membrane proteins, few of the borrelial outer membrane proteins (OMPs) have been identified and characterized to date. Therefore, we utilized a consensus computational network analysis to identify novel borrelial OMPs.

Results: Using a series of computer-based algorithms, we selected all protein-encoding sequences predicted to be OM-localized and/or to form $\beta$-barrels in the borrelial OM. Using this system, we identified 41 potential OMPs from B. burgdorferi and characterized three (BB0838, BB0405, and BB0406) to confirm that our computer-based methodology did, in fact, identify borrelial OMPs. Triton X-114 phase partitioning revealed that BB0838 is found in the detergent phase, which would be expected of a membrane protein. Proteolysis assays indicate that BB0838 is partially sensitive to both proteinase $\mathrm{K}$ and trypsin, further indicating that BB0838 is surface-exposed. Consistent with a prior study, we also confirmed that BB0405 is surface-exposed and associates with the borrelial OM. Furthermore, we have shown that BB0406, the product of a co-transcribed downstream gene, also encodes a novel, previously uncharacterized borrelial OMP. Interestingly, while BB0406 has several physicochemical properties consistent with it being an OMP, it was found to be resistant to surface proteolysis. Consistent with BB0405 and BB0406 being OMPs, both were found to be capable of incorporating into liposomes and exhibit pore-forming activity, suggesting that both proteins are porins. Lastly, we expanded our computational analysis to identify OMPs from other borrelial organisms, including both Lyme disease and relapsing fever spirochetes.

Conclusions: Using a consensus computer algorithm, we generated a list of candidate OMPs for both Lyme disease and relapsing fever spirochetes and determined that three of the predicted B. burgdorferi proteins identified were indeed novel borrelial OMPs. The combined studies have identified putative spirochetal OMPs that can now be examined for their roles in virulence, physiology, and disease pathogenesis. Importantly, the studies described in this report provide a framework by which OMPs from any human pathogen with a diderm ultrastructure could be cataloged to identify novel virulence factors and vaccine candidates.
\end{abstract}

Keywords: Borrelia, Lyme disease, Relapsing fever, Outer membrane proteins

\footnotetext{
*Correspondence: darrin-akins@ouhsc.edu

'Department of Microbiology and Immunology, University of Oklahoma

Health Sciences Center, Oklahoma City, Oklahoma 73104, USA

Full list of author information is available at the end of the article
} 


\section{Background}

Pathogenic spirochetes belonging to the genus Borrelia cause Lyme disease and relapsing fever, both of which are vector-borne illnesses. Lyme disease is caused by pathogenic spirochetes of the Borrelia burgdorferi sensu lato complex which are transmitted to humans through the bite of hard-bodied Ixodes ticks $[1,2]$. The earliest manifestations of Lyme disease include a characteristic skin rash, termed erythema migrans, along with concomitant flu-like symptoms followed by disorders of the heart, nervous system, and joints [1]. Globally, most cases of Lyme disease can be attributed to three Borrelia genospecies, $B$. burgdorferi sensu stricto (hereafter referred to as $B$. burgdorferi), B. afzelii, and B. garinii. In recent years, however, the number of genospecies associated with Lyme disease has expanded to include other organisms such as B. bissettii, B. valaisiana, B. spielmanii, and B. lusitaniae [3-7]. A second group of Borrelia spirochetes including $B$. hermsii, $B$. recurrentis, $B$. duttonii, B. parkeri, B. crocidurae, B. miyamotoi, and $B$. turicatae, are the causative agents of relapsing fever, a disease characterized by recurring episodes of fever with muscle and joint aches [8, 9]. Relapsing fever Borrelia are generally transmitted to humans by a soft-bodied tick of the genus Ornithodoros; however, one genospecies, $B$. recurrentis, is transmitted by the body louse [2].

Similar to Gram-negative organisms, Borrelia spirochetes are dual-membrane organisms with both an inner membrane and an outer membrane (OM); however, Borrelia species lack lipopolysaccharide [10, 11]. Instead, the surface of Borrelia spirochetes is characterized by the presence of numerous surface-exposed lipoproteins that are attached to the outer leaflet of the OM via $\mathrm{N}$-terminal lipid moieties [12]. Borrelial lipoproteins have been the focus of intense study for several decades and are known to be important in virulence and host-pathogen interactions [11, 13-23]. Many of the borrelial lipoproteins are plasmidencoded and differentially expressed throughout the life cycle of the organism [23-28].

The OM of Gram-negative organisms contain membrane-spanning, outer membrane proteins (OMPs) that form amphipathic $\beta$-barrels that can typically form nonspecific or substrate-specific OM pores [29, 30]. Freeze-fracture electron microscopy of the B. burgdorferi OM confirmed that the borrelial OM also possess integral OMPs, although the number of OMPs in the borrelial $\mathrm{OM}$ is at least 10 -fold reduced as compared to Escherichia coli [31, 32]. The Borrelia OMPs identified to date are implicated in nutrient acquisition, antibiotic resistance, host-pathogen interactions, protein transport and assembly, and pore formation
[33-42]. These proteins are characterized by their OM-localization and/or surface exposure but are not lipid-modified lipoproteins. Unlike the majority of the surface-exposed lipoproteins, all of the borrelial OMPs identified thus far are encoded on the $\sim 900 \mathrm{kB}$ linear chromosome [11, 33, 39, 41, 43-46]. While it is known that the borrelial OM contains membrane spanning OMPs with $\beta$-barrel structure and/or poreforming capabilities that are important in overall physiology and host interactions, fewer than 10 borrelial proteins have been identified as potential OMPs and only half of those have thus far been characterized [22, 33, 39, 41, 45-52]. Of the known borrelial OMPs, B. burgdorferi proteins BamA (BB0795), BesC (BB0142), DipA (BB0418), P66 (BB0603), and P13 (BB0034) have been shown to form a $\beta$-barrel, to form pores in the borrelial OM, or to be functional orthologs to known OMPs. Efforts to identify novel OMPs in Borrelia spirochetes have been hindered for several reasons, including the low abundance of borrelial OMPs in the Borrelia OM and the unique fragility of the borrelial OM. Moreover, few orthologs to well-characterized proteins from other bacterial organisms have been identified through sequence comparison analyses [11, 20].

Given the challenges of identifying borrelial OMPs using conventional biochemical and proteomic approaches, we created a bioinformatics approach that utilizes an algorithm for predicting OMPs based on their unique properties and secondary structures. Using the derived computer-based algorithm, we examined chromosomally encoded proteins from both Lyme disease and relapsing fever Borrelia to identify candidate proteins that were both conserved and predicted to be OMPs in the genus Borrelia. Known borrelial OMPs were identified on the final candidate OMP list; and, importantly, three of the previously uncharacterized $B$. burgdorferi proteins identified by this method (BB0838, BB0405, and BB0406) were confirmed to be OMPs, indicating the computerbased methodology could, in fact, predict novel borrelial OMPs. Specifically, we determined that the $B$. burgdorferi protein BB0838 is amphiphilic and has surface-exposed regions that were accessible to proteases. B. burgdorferi BB0405 was previously shown by our laboratory to be a surface-exposed protein that localized to the OM [22, 39], and BB0405 and BB0406 were detected in OM vesicles by Pal and colleagues in a study examining the overall protein and lipoprotein content of the borrelial OM [53]. Herein, we found that BB0406 was indeed amphiphilic and localized to the $B$. burgdorferi $\mathrm{OM}$ as shown previously for BB0405 and that both BB0405 and BB0406 are pore-forming proteins. 


\section{Results}

Computational framework for predicting Borrelia burgdorferi B31 outer membrane proteins

To date, few B. burgdorferi outer membrane proteins (OMPs) have been identified [22, 33, 39, 41, 50]; therefore, we aimed to identify novel B. burgdorferi B31 OMPs that are localized to the OM but are not borrelial lipoproteins. We used a bioinformatics strategy (outlined in Fig. 1) modified from one used recently to predict OMPs in the spirochete Treponema pallidum [54]. Given that all Borrelia OMPs identified to date are chromosomally encoded and that we anticipate chromosomally encoded proteins will be more conserved among
Borrelia strains [33, 39, 41, 46, 50], we focused on identifying novel OMPs encoded on the B. burgdorferi B31 chromosome. As summarized in Fig. 1, to generate a list of candidate $B$. burgdorferi OMPs, we eliminated predicted lipoproteins and proteins predicted to contain transmembrane $\alpha$-helices, retained protein sequences predicted to be OM-localized and/or to form $\beta$-barrels, removed sequences that were orthologous to known non-OMPs, and retained proteins with predicted $\mathrm{N}$ terminal signal peptides. More specifically, all protein sequences encoded from the B. burgdorferi B31 chromosome were first analyzed for their potential to be a spirochaetal lipoprotein according to the methods

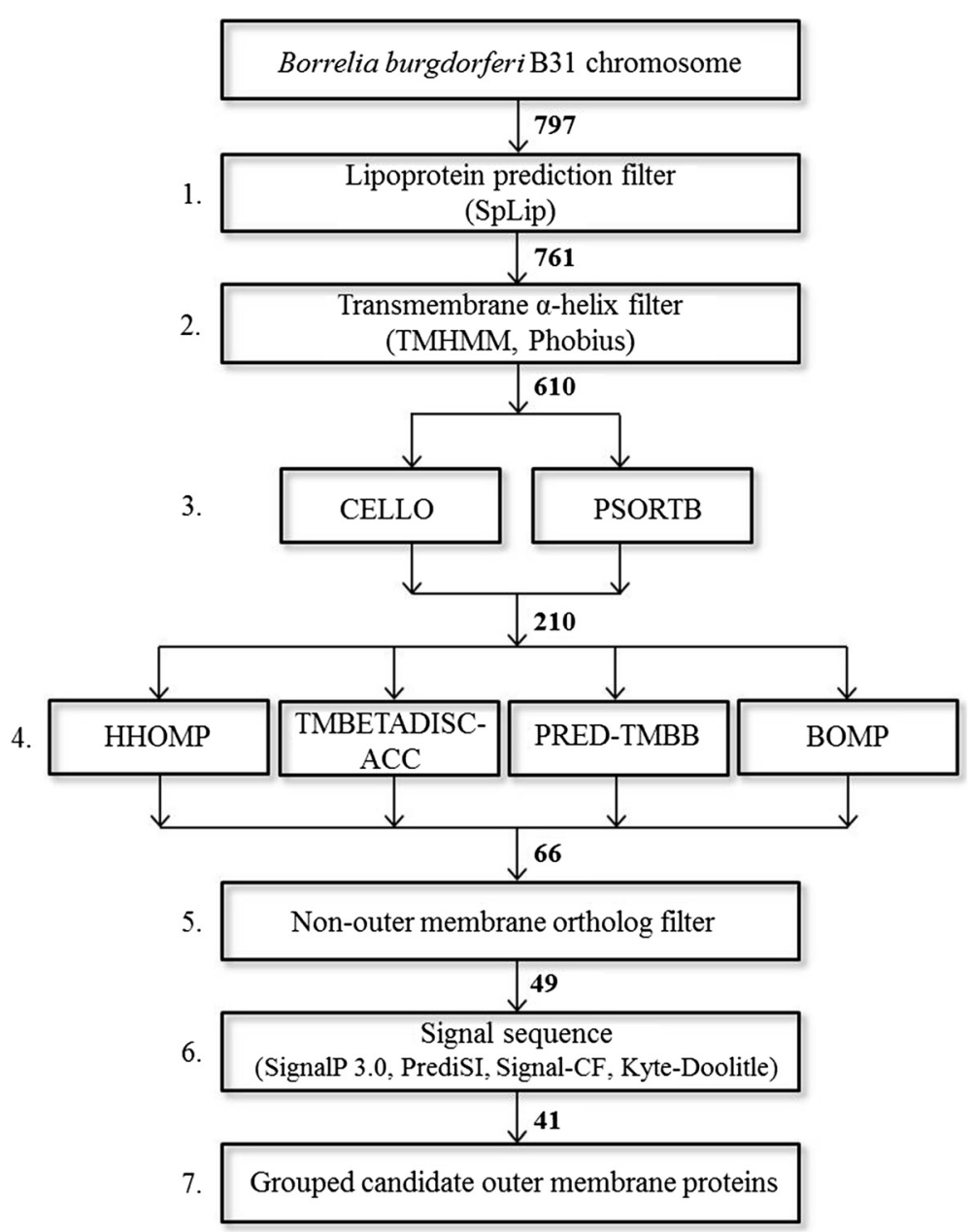

Fig. 1 Computational framework for predicting OM-localized, $\beta$-barrel proteins from B. burgdorferi B31. All proteins encoded on the B. burgdorferi B31 chromosome were subjected to filters as shown. The following steps outline the computational framework utilized in the study: (1) proteins predicted to be spirochaetal lipoproteins were discarded, (2) proteins predicted to contain transmembrane a-helices by one of two programs were discarded, (3) proteins predicted to be OM-localized by one of two programs were retained, (4) proteins predicted to form a $\beta$-barrel by at least one of four or two of four $\beta$-barrel prediction programs depending on if the sequences was predicted to be OM-localized by two or one of the OM-localization programs were retained, (5) proteins orthologous to known non-OMPs were discarded, (6) proteins predicted to have a N-terminal signal peptide by at least one of four programs were retained, and (7) the remaining proteins were categorized by the number of programs predicting OM-localization or propensity to form a $\beta$-barrel. The number of sequences remaining after each filter are indicated. Proteins were removed from the candidate OMP list if the sequence was not predicted to be OM localized and have $\beta$-barrel conformation by three of the following six algorithims: CELLO, pSORTb, HHOMP, TMBETADISC-AAC, PRED-TMBB, and BOMP 
described by Setubal, et al. [55] and/or to contain transmembrane $\alpha$-helices by either one of two algorithms [Phobius [56] and TMHMM [57]]. As neither of these properties are characteristic of integral OMPs, all sequences predicted to encode membrane anchored lipoproteins or to contain one or more alpha-helical transmembrane domains were eliminated from the candidate OMP list. The 610 sequences remaining were then examined for their likelihood to encode a protein localized to the $\mathrm{OM}$ and predicted to form a $\beta$-barrel. Any sequence predicted to be OM-localized by one of two programs that predict cellular localization [CELLO [58] and/or pSORTb 3.0 [59]] was retained as a candidate OMP and was then examined for $\beta$-barrel topology given that all structurally characterized OMPs from diderm organisms form $\beta$-barrels. The programs HHOMP [60], TMBDISC-ACC [61], PRED-TMBB [62], and BOMP [63] were used to examine $\beta$-barrel propensity, and proteins were retained if they were predicted to be a $\beta$-barrel by at least one of the four or two of the four $\beta$-barrel prediction programs depending on if the sequence was predicted to be OM-localized by two or one of the OM-localization programs, respectively. Next, any sequence orthologous to proteins that are known not to be OMPs in other organisms were excluded from the list of candidate borrelial OMPs. Finally, we also analyzed the first 60 amino acids of the remaining sequences for the presence of a canonical N-terminal signal peptide. Given that proteins localized to the OM would require a signal peptide, we removed from the list any protein not predicted to have a signal peptide by at least one of four signal peptide prediction programs [64-67]. A final list of 41 B. burgdorferi B31 candidate OMPs was compiled (Table 1). To further prioritize this list, we categorized sequences according to the number of computational programs predicting OM localization and/or $\beta$-barrel topology from the following six programs mentioned above: CELLO, pSORTb 3.0, HHOMP, TMBDISC-ACC, PRED-TMBB, and BOMP. For instance, our highest priority candidate OMPs are those sequences for which all six programs predicted the encoded protein to be an OMP, and we considered any that were predicted by three or more of the localization and/or $\beta$-barrel topology programs to be putative OMPs worthy of further analysis.

Importantly, we identified several known borrelial OMPs by the computational framework utilized suggesting that the algorithm was effective at identifying OMPs encoded in the B. burgdorferi B31 genome. Within the first group of candidate OMPs (i.e., Group 1; sequences predicted to be OMPs by all six programs utilized in the study) were two borrelial proteins previously identified and characterized as OMPs: BamA [39] and the poreforming OMP DipA [41] (Table 1). Furthermore, we also identified in Group 2 (predicted as an OMP by 5 of 6 programs) the borrelial OMP P66 (BB0603), a known adhesin that binds $\beta_{3}$-integrins [34-37], has porin activity [50], and adopts a $\beta$-barrel conformation [51]. In Group 3 (predicted as an OMP by 4 of 6 programs), the known OMP BesC [33] was also identified using the algorithm outlined. Notably, Pal and colleagues previously identified borrelial proteins associated with OM complexes from B. burgdorferi B31 [53]. When we compared our list of candidate OMPs with the list of proteins detected in the borrelial $\mathrm{OM}$ in this prior report, we found numerous similarities, including the known borrelial OMPs DipA, BamA, P66, and $\mathrm{BesC}$ as well as the hypothetical proteins BB0543, BB0662, BB0125, BB0405, and BB0406.

In addition to the known borrelial OMPs identified in Group 1, two uncharacterized hypothetical proteins, BB0794 and BB0838, were also predicted as potential candidate OMPs in this first group (Table 1). The protein BB0794 is encoded by an ORF situated directly upstream of BamA, which is a known OMP. BB0794 has a conserved DUF490 domain which has been reportedly found in TamB orthologs [68]. While TamB is actually an inner membrane protein that is part of the translocation and assembly module (TAM), the C-terminus of TamB is predicted to have $\beta$-sheet topology and has been predicted by numerous computer-based prediction programs to be similar to a $\beta$-barrel OMP [69-72]. Given this previous work with TamB from other organisms, it is not surprising that BB0794 was identified as a candidate OMP in our studies. BB0838, also identified in Group 1, is encoded by an ORF downstream of $B$. burgdorferi B31 uvrA and $u v r B$, which encode proteins involved in nucleotide excision repair [73, 74]. Interestingly, BB0838 has a conserved LptD (lipopolysaccharide transport protein D) domain, which is the known OM, $\beta$-barrel component of the translocation complex that transports lipopolysaccharide (LPS) to the cell surface $[75,76]$.

Unlike the first three groups, no fully characterized borrelial OMPs were included in the Group 4 list of candidates that were predicted to be an OMP by 3 of the 6 localization and topology programs. It should be noted, however, that BB0405 was identified in Group 4, and we have previously reported that BB0405 is likely localized to the $\mathrm{OM}$, is amphiphilic, and appears to be surfaceexposed [22, 39]. The paralogous BB0406 (59\% sequence similarity to BB0405), encoded by the ORF immediately downstream of BB0405, also was included in this group of candidates.

\section{B. burgdorferi B31 BB0838 is a surface-exposed, amphiphilic protein}

To confirm that the computational method utilized to screen for candidate proteins did, in fact, correctly 
Table 1 Borrelia burgdorferi B31 candidate OMPs

\begin{tabular}{|c|c|c|c|c|c|c|c|c|c|c|}
\hline \multirow[t]{2}{*}{ Protein } & \multicolumn{6}{|c|}{ Outer membrane localization/ $\beta$-barrel conformation ${ }^{a}$} & \multicolumn{4}{|c|}{ Signal sequence ${ }^{b}$} \\
\hline & $\overline{\text { CELLO }}$ & PSORTb & HHOMP & TMBETADISC -ACC & PRED-TMBB & $\overline{B O M P}$ & SignalP 3.0 & Predisl & Signal-CF & Kyte Doolittle \\
\hline \multicolumn{11}{|l|}{ Group $1(6 / 6)$} \\
\hline BB0418 (DipA) & + & + & + & + & + & + & + & + & + & + \\
\hline BB0794 & + & + & + & + & + & + & - & + & + & + \\
\hline BB0795 (BamA) & + & + & + & + & + & + & - & + & + & + \\
\hline BB0838 & + & + & + & + & + & + & + & + & + & + \\
\hline \multicolumn{11}{|l|}{ Group 2 (5/6) } \\
\hline BB0110 & + & + & + & + & + & - & - & - & - & + \\
\hline BB0236 & + & + & - & + & + & + & - & + & - & + \\
\hline BB0603 (P66) & + & + & + & + & + & - & + & + & + & + \\
\hline BB0667 & + & + & - & + & + & + & - & + & - & + \\
\hline BB0811 & + & + & - & + & + & + & + & + & + & + \\
\hline BB0824 & + & - & + & + & + & + & - & + & + & + \\
\hline \multicolumn{11}{|l|}{ Group 3 (4/6) } \\
\hline BB0027 & + & - & + & + & + & - & - & - & + & + \\
\hline BB0089 & + & + & - & + & - & + & + & + & + & + \\
\hline BB0142 (BesC) & + & - & + & + & + & - & - & - & - & + \\
\hline BB0156 & + & + & - & + & + & - & - & - & + & + \\
\hline BB0159 & + & + & - & + & + & - & + & - & - & + \\
\hline BB0161 & + & + & + & - & - & + & - & - & - & + \\
\hline BB0308 & + & + & - & + & - & + & - & + & + & + \\
\hline BB0319 & + & + & - & + & - & + & - & - & - & + \\
\hline BB0464 & + & + & - & + & - & + & + & + & + & + \\
\hline BB0465 & + & + & + & - & + & - & - & + & + & + \\
\hline BB0543 & - & + & + & + & + & - & - & + & + & + \\
\hline BB0564 & - & + & + & + & + & - & - & - & - & + \\
\hline BB0624 & + & + & - & + & + & - & - & - & - & + \\
\hline BB0662 & + & + & - & + & + & - & - & + & - & + \\
\hline BB0743 & + & + & - & + & - & + & - & + & - & + \\
\hline BB0761 & + & + & - & + & - & + & - & - & - & + \\
\hline \multicolumn{11}{|l|}{ Group $4(3 / 6)$} \\
\hline BB0032 & + & + & - & + & - & - & - & - & + & + \\
\hline BB0039 & + & - & - & + & - & + & - & + & + & + \\
\hline BB0043 & + & - & - & + & + & - & - & - & + & + \\
\hline BB0058 & + & - & - & + & - & + & + & + & + & + \\
\hline BB0102 & + & + & - & + & - & - & + & + & - & - \\
\hline BB0125 & + & + & - & + & - & - & - & - & + & - \\
\hline BB0165 & + & + & - & + & - & - & - & - & - & + \\
\hline BB0322 & + & + & + & - & + & - & - & - & - & + \\
\hline BB0352 & + & + & - & + & - & - & + & + & - & + \\
\hline BB0405 & - & + & + & - & + & - & - & + & + & + \\
\hline BB0406 & + & + & + & - & - & - & + & + & - & + \\
\hline BB0458 & + & + & - & + & - & - & - & + & - & + \\
\hline
\end{tabular}


Table 1 Borrelia burgdorferi B31 candidate OMPs (Continued)

\begin{tabular}{|c|c|c|c|c|c|c|c|c|c|c|}
\hline BB0546 & + & + & - & + & - & - & - & - & + & + \\
\hline BB0735 & + & + & - & + & - & - & - & + & + & + \\
\hline BB0790 & + & - & - & + & - & + & - & - & + & + \\
\hline
\end{tabular}

${ }^{a}$ Proteins are grouped according to the number of OM prediction programs that predict localization to the OM or $\beta$-barrel formation. The outer membrane protein prediction programs included CELLO, PSORTb, HHOMP, TMBETADISC-ACC, PRED-TMBB and BOMP

${ }^{b}$ Signal sequences were predicted by the programs SignalP 3.0, PrediSi, and Signal-CF. Signal sequences were also manually inspected by hydrophilicity plots generated according to the methods of Kyte and Doolittle

identify novel OMPs from B. burgdorferi, we next examined the cellular localization of specific candidate OMPs identified. As mentioned above, Group 1 contained the candidate BB0838 (Table 1) that encodes an LptD domain, which is a characteristic of LptD proteins known to contain a C-terminal $\beta$-barrel region. Consistent with BB0838 being a putative OMP, when BB0838 was modeled without a specified template using the ITASSER [77-79] and SPARKS-X [80] programs, LptD proteins were identified as the top hit for structural modeling similarities in all cases. BB0838 is predicted to be approximately $120 \mathrm{kDa}$ and is encoded downstream of $u v r B$ and $u v r A$. Given that $u v r B, u v r A$, and $b b 0838$ were all located in close proximity on the chromosome, with the $u v r A$ and $b b 0838$ ORFs overlapping, we first examined whether these genes were part of an operon using RT-PCR. This analysis confirmed that $u v r B, u v r A$, and $b b 0838$ are encoded on the same transcript (Fig. 2a).

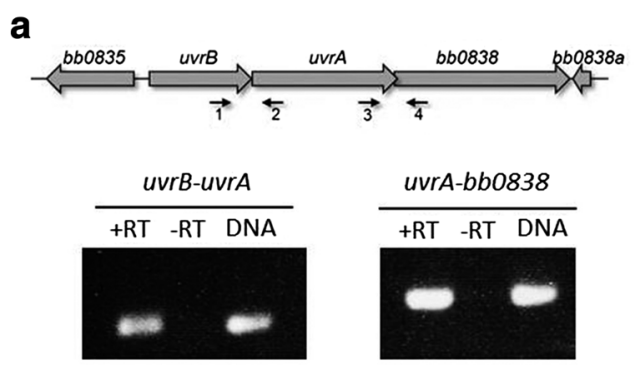

b
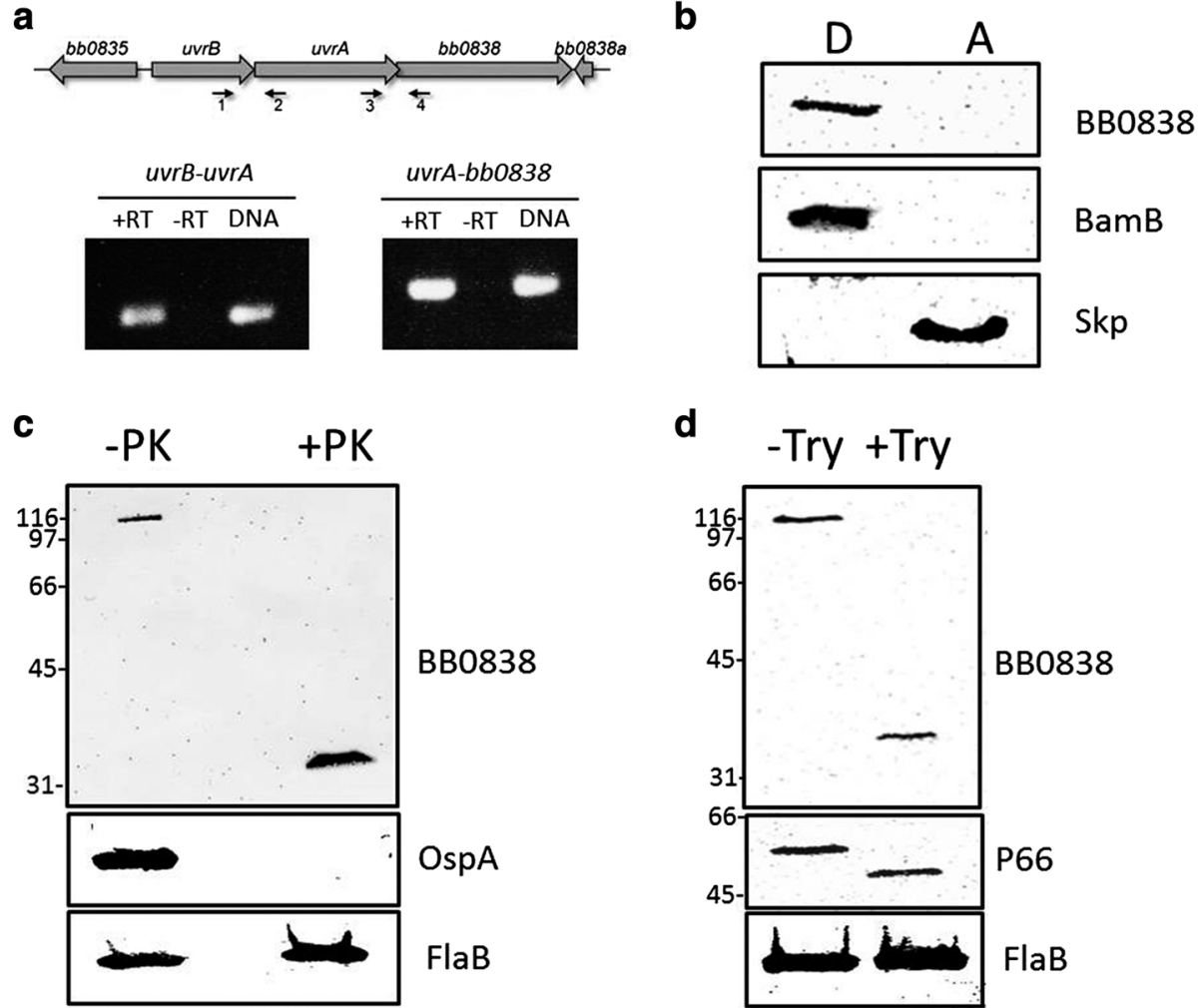

Fig. 2 B. burgdorferi B31 BB0838 is surface localized and amphiphilic. a. bb0838 is in an operon with uvrA and uvrB. Schematic of the uvrB, uvrA, and bb0838 operon is shown in the top panel. Total RNA was isolated from B. burgdorferi B31 cells and used for RT-PCR using primer pairs listed in Table 3. Primer pairs were used that amplify a region traversing uvrB and uvrA (primers 1 and 2, left panel) and uvrA and bb0838 (primers 3 and 4, right panel). A negative control lacking RT was used as template for the RT-PCR (-RT) as was as a positive control in which genomic DNA instead of CDNA was used as template (DNA). b. Triton X-114 phase partitioning of B. burgdorferi B31 whole-cell lysates was performed to separate soluble, aqueous (A) phase proteins from amphiphilic, detergent (D) phase proteins. Aqueous and detergent fractions were separated by SDS-PAGE and immunoblotted with anti-BB0838 peptide antibodies. Equivalent fractions were also immunoblotted with anti-BamB and anti-Skp antibodies as detergent-enriched and aqueous-enriched controls, respectively. c-d. Whole-cell lysates were washed and incubated with (c) proteinase K (PK) or (d) trypsin. Samples were then immunoblotted with BB0838 peptide antibodies to assess surface degradation of BB0838. Equivalent samples were also immunoblotted with OspA antibodies or P66 antibodies for PK and trypsin experiments, respectively, to control for protease activity and with antibodies that recognize the periplasmic protein FlaB to ensure that the OM remained intact throughout the proteolysis experiments. Molecular weight standards (in $\mathrm{kDa}$ ) are shown at left 
We next examined whether BB0838 is membraneassociated by performing Triton X-114 phase partitioning studies to separate membrane proteins from soluble cytoplasmic and periplasmic proteins [81]. BB0838 partitioned into the detergent-enriched fractions after Triton X-114 phase partitioning of B. burgdorferi B31 wholecell lysates suggesting that BB0838 has the properties expected of an amphiphilic membrane protein (Fig. $2 \mathrm{~b}$ ). For phase partitioning experiments, the lipoprotein BamB [42] served as a membrane protein control, while the soluble Skp protein partitioned into the aqueous phase as expected (Fig. 2b).

To assess whether BB0838 is surface-exposed, B. burgdorferi $\mathrm{B} 31$ cells were treated with protease proteinase $\mathrm{K}$ (PK). Immunoblot analysis of PK treated cells revealed that BB0838 is at least partially susceptible to PK degradation suggesting that the protein has surface-exposed regions (Fig. 2c). In fact, PK treatment resulted in a breakdown of the full length protein of approximately $120 \mathrm{kDa}$ to a smaller protein band of approximately $33 \mathrm{kDa}$ (Fig. 2c). To further characterize the potential surface-exposed regions of BB0838, we also treated cells with the protease trypsin, which specifically targets the carboxyl side of lysine and arginine residues for proteolysis. Trypsin proteolysis resulted in a degradation pattern similar to PK treatment; however, the breakdown product was slightly larger than the protein band detected when cells were treated with PK (Fig. 2d). For both PK and trypsin assays, known PK and trypsin sensitive proteins OspA and P66, respectively, were degraded in the presence of the enzyme as expected (Fig. 2c-d). Furthermore, the periplasmic FlaB protein was not degraded in either experiment and served as a control for membrane integrity throughout the proteolysis studies (Fig. 2c-d).

\section{B. burgdorferi B31 BB0405 and BB0406 are amphiphilic and OM-localized}

Both B. burgdorferi BB0405 and BB0406 were detected in Group 4 of the candidate OMP list (Table 1). The prior observations suggesting that BB0405 is surfaceand OM-localized [22,39], combined with the observation that BB0405 and BB0406 are detected in OM vesicles isolated from B. burgdorferi B31 [53], strongly suggested that Group 4 also contained novel OMPs that warranted further characterization. Thus, we next examined the cellular localization and physicochemical properties of the two Group 4 proteins BB0405 and BB0406. We first looked more closely at the genomic organization of $b b 0405$ and $b b 0406$ and found that $b b 0405$ overlaps with the upstream gene $b b 0404$. Therefore, we examined whether these genes were cotranscribed with the bb0404. RT-PCR utilizing primers that amplified regions traversing bb0404 and bb0405 as well as $b b 0405$ and $b b 0406$ revealed that all three genes are co-expressed in a single transcript (Fig. 3a). Triton $\mathrm{X}-114$ phase partitioning experiments revealed that both BB0405 and BB0406 are membrane proteins as they both partitioned into the detergent-enriched phase (Fig. 3b). Equivalent fractions were also immunoblotted with anti-BamB antibodies and anti-Skp antibodies which served as membrane and soluble protein controls, respectively (Fig. $3 \mathrm{~b}$ ). Since phase partitioning experiments suggested BB0405 and BB0406 are amphiphilic, we next examined whether they are localized to the borrelial OM. OMs and protoplasmic cylinders (PC) were enriched from B. burgdorferi $\mathrm{B} 31$ cells and subsequently immunoblotted (Fig. 3c). BB0405 and BB0406 were detected in the $\mathrm{OM}$ fractions indicating both are OMPs (Fig. 3c). BamA, a known B. burgdorferi B31 OMP, was detected in the OM as expected, while the inner membrane lipoprotein OppAIV was detected only in the $\mathrm{PC}$ fraction indicating the $\mathrm{OM}$ fraction was highly enriched (Fig. 3c).

Given that BB0405 and BB0406 are OM-localized and display the properties expected of OMPs, we next examined whether BB0405 and BB0406 are also surfaceexposed. PK surface-localization assays were performed and PK treated and sham treated cell lysates were immunoblotted with BB0405 and BB0406 antibodies. Surprisingly, while BB0405 was partially PK sensitive with only an $\sim 10 \mathrm{kDa}$ region of 405 being protected from the PK degradation, BB0406 was entirely PK resistant (Fig. 3d). This suggested that BB0406 is either not surfaceexposed or is protease resistant. OspA served as a positive control in the PK experiments (Fig. 3d). To confirm that the $\mathrm{OM}$ remained intact during PK surface proteolysis, equivalent membranes were also immunoblotted with anti-FlaB antibodies to demonstrate that the periplasmic FlaB protein was not exposed to PK degradation (Fig 3d).

\section{B. burgdorferi B31 BB0405 and BB0406 associate with and form pores in LUVs}

Since both BB0405 and BB0406 are associated with the $\mathrm{OM}$, we next wanted to determine if these proteins could integrate into lipid bilayers and form pores. To examine whether folded recombinant $B$. burgdorferi BB0405 and BB0406 could incorporate into large unilamellar vesicles (LUVs) that were generated to mimic the phospholipid content of the B. burgdorferi B31 OM [82], LUVs were incubated separately with folded recombinant BB0405 or BB0406. The mixture was then separated on discontinuous sucrose gradients to separate the liposome-containing top fraction (TF) from the bottom fraction (BF), which contains unincorporated protein. Fractions were then subjected to immunoblot analysis with antisera directed against BB0405 or BB0406. Both 

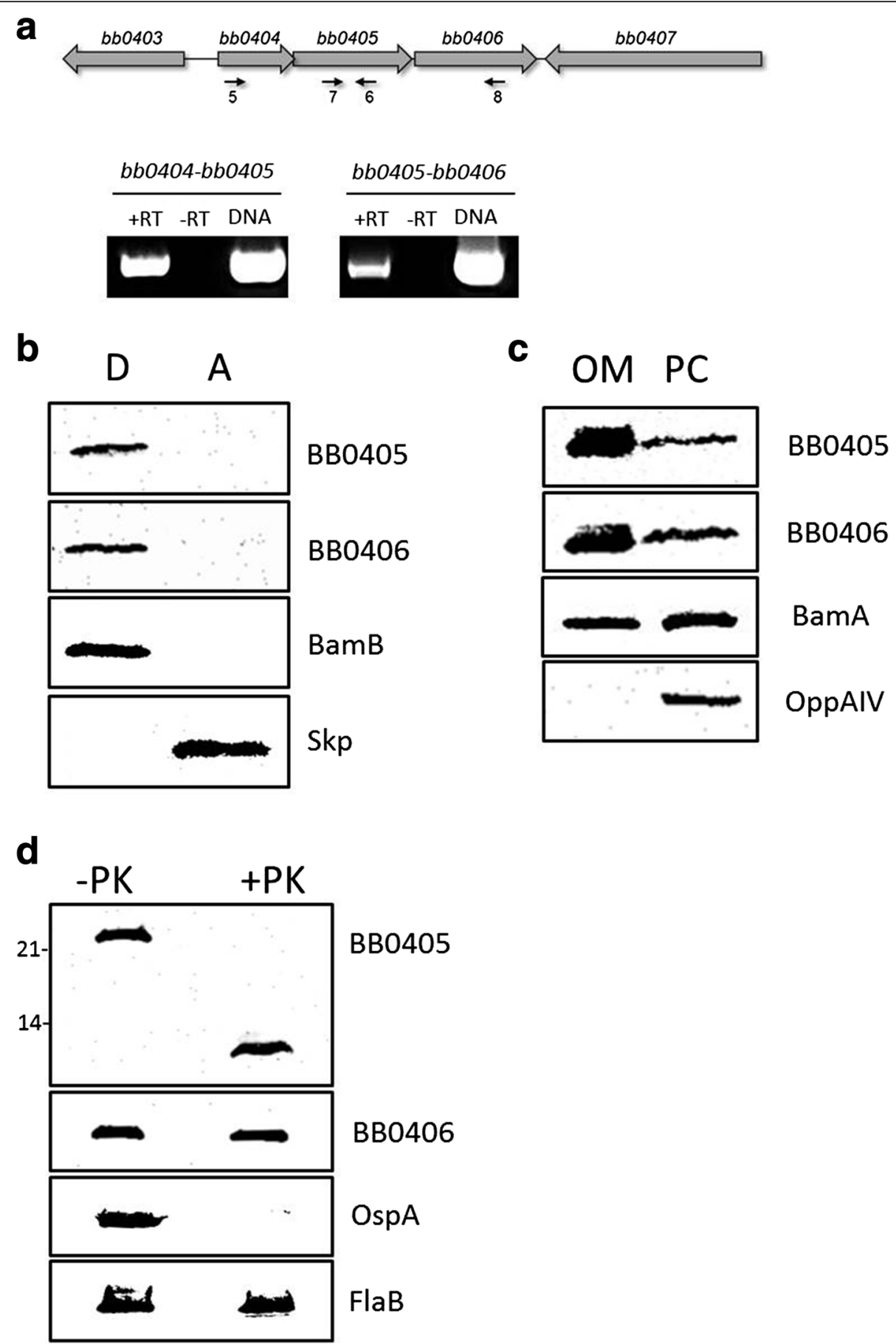

Fig. 3 (See legend on next page.) 
(See figure on previous page.)

Fig. 3 B. burgdorferi B31 BB0406 is amphiphilic and OM-associated. a. bb0404, bb0405, and bb0406 are transcribed as an operon. Schematic of the b60404, bb0405, and bb0406 operon is shown in the top panel. Total RNA was isolated from B. burgdorferi B31 cells and used for RT-PCR using primer pairs listed in Table 3. Primer pairs were used that amplify a region traversing bb0404 and bb0405 (primers 5 and 6, left panel) and bb0405 and bb0406 (primers 7 and 8, right panel). A negative control without RT was used as template for the RT-PCR (-RT) as was as a positive control in which genomic DNA instead of CDNA was used as template (DNA). b. Triton X-114 phase partitioning of B. burgdorferi B31 whole-cell lysates were performed to separate aqueous-enriched (A) proteins from detergent-enriched (D) proteins. Aqueous and detergent fractions were separated by SDS-PAGE and immunoblotted with rat anti-BB0405 and rat anti-BB0406 antibodies. As controls, equivalent fractions were also immunoblotted with antibodies directed against the detergent-soluble lipoprotein BamB and the soluble, periplasmic protein Skp. c. Outer membrane $(\mathrm{OM})$ and protoplasmic cylinder $(\mathrm{PC})$ fractions were isolated from B. burgdorferi B31. Subsequently, OM and PC fractions were immunoblotted with rat anti-BB0405 and anti-BB0406 antibodies. Equivalent membranes were also subjected to immunoblot with BamA and OppAlV antibodies. d. Whole-cell lysates were washed and incubated with proteinase K (PK). Samples were then immunoblotted with BB0405 or BB0406 antibodies to assess surface degradation of the protein. Equivalent samples were also immunoblotted with OspA antibodies to control for protease activity and with antibodies that recognize the periplasmic protein FlaB to ensure that the OM remained intact throughout the proteolysis experiments

proteins were detected in the TF suggesting that BB0405 and BB0406 were able to incorporate into liposomes (Fig. 4a). When experiments were also performed with folded recombinant $E$. coli OmpA, a well characterized OM protein [83], OmpA was also detected in the TF (Fig. 4a). As expected, the soluble GST protein was unable to incorporate into LUVs and was thus only detected in the BF (Fig. 4a).

We next assessed whether BB0405 and BB0406 had porin like properties and could form pores in LUVs using a pore formation assay to measure efflux of fluorophore $\mathrm{Tb}(\mathrm{DPA})_{3}^{3-}$ from liposomes incubated with the folded recombinant protein. When liposomes were loaded with folded BB0405 or BB0406 protein, fluorophore efflux from the loaded liposomes was detected (Fig. 4b), indicating that both proteins were capable of forming pores. Escape of the fluorophore was also detected when liposomes were incubated with the known pore-forming E. coli protein OmpF as well as the $B$. burgdorferi B31 P66 protein (Fig. 4b), which we have previously shown forms pores in LUVs [51]. In contrast, E. coli OmpA, which occurs mostly in a closed conformation, did not efficiently generate pores in the LUVs, and thus only low levels of efflux was detected (Fig. 4b), which is entirely consistent with previous reports [84, 85]. Taken together these studies suggest that both BB0405 and BB0406 are OM-localized proteins capable of forming pores.

\section{OMP candidate proteins from Lyme disease and relapsing fever Borrelia}

After demonstrating that the computational analysis could accurately predict novel $B$. burgdorferi OMPs, we expanded our computational analysis to predict OMPs from spirochetes belonging to both the Lyme diseaseand relapsing fever-causing groups (see Table 2). In broadening the scope of the study, we looked specifically for OMPs conserved among all Borrelia genospecies that
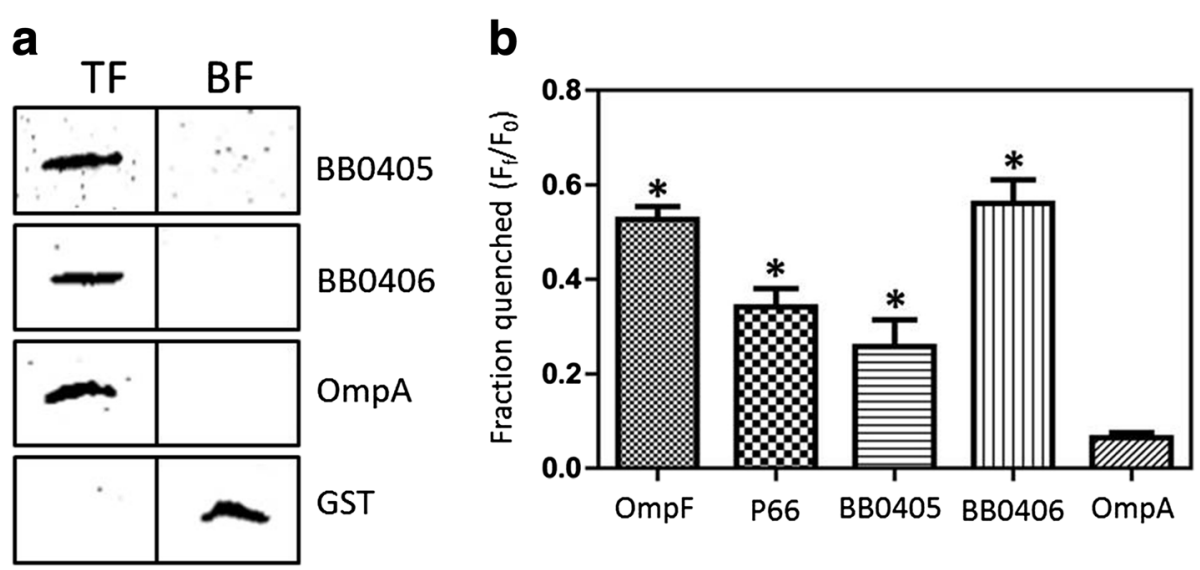

Fig. 4 a. Liposomes simulating the B. burgdorferi B31 OM were incubated with recombinant BB0405, BB0406, E. coli OmpA, or GST and then separated on discontinuous sucrose gradients. Gradient fractions were collected from the top (TF) and bottom (BF) and subjected to immunoblot with appropriate antibodies. b. Liposomes loaded with the fluorophore Tb(DPA) ${ }_{3}^{3-}$ were incubated with recombinant B. burgdorferi B31 BB0405, BB0406, P66, E. coli OmpF, or E. coli OmpA in buffer supplemented with EDTA, and fluorophore efflux was measured as quenched fluorescence. Three independent experiments were compared and each bar represents the mean \pm S.E. (error bars). Statistical significance compared with E. coli OmpA is indicated with * $(p<0.05)$ 
Table 2 Borrelia genomes analyzed

\begin{tabular}{|c|c|c|c|c|c|}
\hline Genome analyzed & $\begin{array}{l}\text { Accession } \\
\text { number }\end{array}$ & $\begin{array}{l}\text { Total number of } \\
\text { proteins }\end{array}$ & $\begin{array}{l}\text { Predicted } \\
\text { lipoproteins }\end{array}$ & $\begin{array}{l}\text { Predicted proteins with } \\
\text { trans-membrane domains }\end{array}$ & $\begin{array}{l}\text { Predicted OM/ } \beta \text {-barrel } \\
\text { proteins }\end{array}$ \\
\hline \multicolumn{6}{|l|}{ Lyme disease spirochetes } \\
\hline Borrelia burgdorferi B31 & AE000783.1 & 797 & 36 & 152 & 41 \\
\hline Borrelia burgdorferi ZS7 & СР001205.1 & 808 & 34 & 151 & 41 \\
\hline Borrelia burgdorferi N40 & CP002228.1 & 809 & 34 & 155 & 39 \\
\hline Borrelia burgdorferi JD1 & CP002312.1 & 823 & 39 & 154 & 41 \\
\hline Borrelia burgdorferi CA382 & СР005925.1 & 819 & 34 & 153 & 39 \\
\hline Borrelia garinii BgVir & СР003151.1 & 826 & 33 & 157 & 40 \\
\hline Borrelia garinii NMJW1 & СР003866.1 & 813 & 28 & 150 & 35 \\
\hline Borrelia garinii Pbi & СР000013.1 & 825 & 33 & 158 & 38 \\
\hline Borrelia afzelii HLJ01 & СР003882.1 & 892 & 27 & 161 & 42 \\
\hline Borrelia afzelii PKo & CP002933.1 & 824 & 31 & 159 & 36 \\
\hline Borrelia valaisiana VS116 & ABCY02000001.1 & 832 & 31 & 163 & 37 \\
\hline Borrelia bissettii DN127 & СР002746.1 & 816 & 28 & 157 & 42 \\
\hline \multicolumn{6}{|l|}{ Relapsing fever spirochetes } \\
\hline Borrelia duttonii Ly & СР000976.1 & 820 & 36 & 164 & 36 \\
\hline $\begin{array}{l}\text { Borrelia crocidurae str. } \\
\text { Achema }\end{array}$ & СР003426.1 & 864 & 30 & 162 & 37 \\
\hline Borrelia parkeri HR1 & СР007022.1 & 825 & 36 & 158 & 27 \\
\hline Borrelia miyamotoi LB-2001 & CP006647.2 & 808 & 27 & 156 & 27 \\
\hline Borrelia turicatae $91 E 135$ & СР000049.1 & 818 & 37 & 164 & 32 \\
\hline Borrelia recurrentis A1 & СР000993.1 & 800 & 32 & 157 & 34 \\
\hline Borrelia hermsii HS1 & CP000048.1 & 819 & 35 & 159 & 40 \\
\hline
\end{tabular}

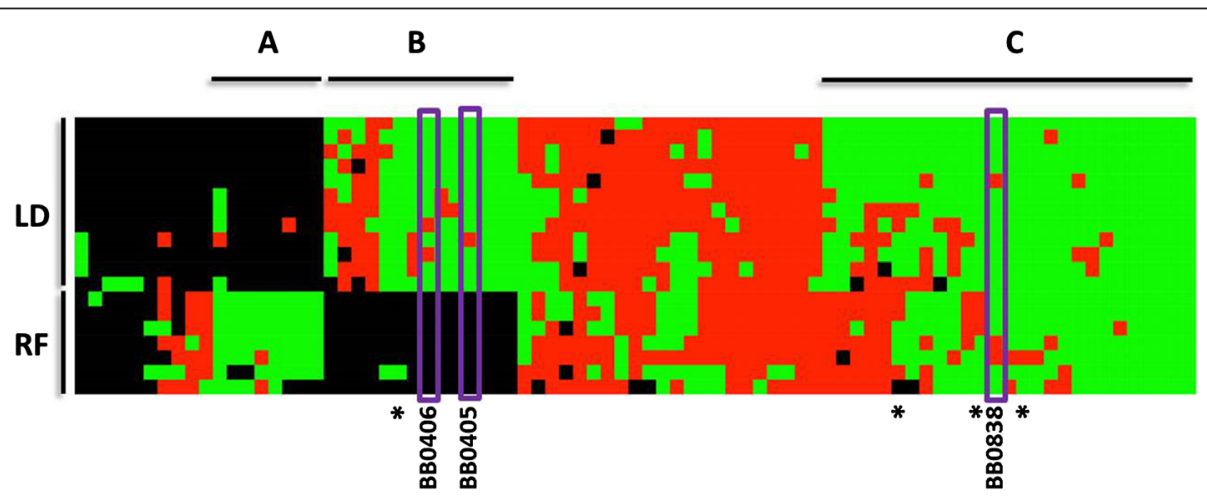

Fig. 5 To assess the value of these predictions to identify putative vaccine immunogens, predicted OMPs from each of the Borrelia genomes were organized into orthologous clusters, and the resulting information was presented as a heat map. In this analysis, clusters of Borrelia proteins predicted to be OMPs are represented as green blocks, while clusters of Borrelia proteins orthologous to these, but not passing all OMP prediction filters are represented in red. If a cluster of orthologous proteins was not encoded in a given borrelial genome, this was represented as a black block. These data were then subject to a two-way hierarchical clustering, by genome and by orthologous protein cluster. From this analysis, three groups of predicted OMPs were identified: Group a represents predicted borrelial OMPs unique to relapsing fever (RF) organisms, Group $\mathbf{b}$ represents predicted borrelial OMPs unique to Lyme disease (LD) pathogens and Group c includes predicted OMPS shared by both LD and RF pathogens. The candidate OMPs analyzed in this study are indicated with purple boxes corresponding to BB0405, BB0406, and BB0838. Asterisks $\left(^{*}\right)$ indicate known borrelial OMPs identified in the study including BamA, P66, BesC, and DipA. A larger version of this figure with cluster IDs and genome designations is provided in Additional file 4: Figure S1 
could be potential universal targets for future vaccine studies. Furthermore, novel OMPs conserved among the Borrelia spp. could be important virulence determinants and relevant in spirochete physiology. For this analysis, all chromosomally encoded proteins from twelve Lyme disease Borrelia including genospecies B. burgdorferi, $B$. garinii, B. afzelii, $B$. valaisiana, and $B$. bissettii and seven relapsing fever Borrelia including $B$. duttonii, B. crocidurae, B. parkeri, B. miyamotoi, B. turicatae, B. recurrentis, and $B$. hermsii were subjected to the same computational analysis as outlined in Fig. 1. All genomes analyzed as well as accession numbers are listed in Table 2, and the data collected for all ORFs are presented in Additional file 1: Table S1 and summarized in Table 2. After collecting the data for all chromosomally encoded protein sequences from nineteen Borrelia organisms, candidate OMPs from each genome were identified using the same process that was described above to identify candidate OMPs from $B$. burgdorferi B31. The candidate OMPs identified from the chromosomes of all nineteen species are listed in Additional file 2: Table S2.

The global analysis of numerous Borrelia genomes allowed us to determine which candidate OMPs are conserved among the various species analyzed. To do this, using CD-hit, we first sorted all protein sequences into orthologous clusters [86] [Additional file 3: Table S3]; these results were then used to construct a heat map [87] that encompassed candidate OMPs specific to relapsing fever spirochetes, Lyme disease spirochetes, or both Lyme disease and relapsing fever spirochetes (Fig. 5 and Additional file 4: Figure S1; predicted OMPs in green). The cluster analysis also included protein-coding sequences in these genomes that were not predicted to be OMPs, but were nevertheless orthologous to one or more predicted OMPs (Fig. 5; orthologs in a cluster not predicted to be OMPs are indicated in red). The heat map also indicates if no ortholog was detected in the cluster for a given genome (Fig. 5; indicated in black). In some clusters, almost all of the orthologs within the cluster were predicted to be OMPs with only a few orthologs not passing the computational analysis used for OMP prediction. Apparent false negative predictions could be identified as the rare ortholog(s) within a single cluster that was not predicted to be an OMP while all of the other cluster members were predicted to be OMPs. Conversely, apparent false positive predictions also were observed that could be visualized as the rare ortholog(s) predicted to be an OMP when the majority of the members of the unique cluster were not predicted OMPs. For instance, BB0838 was predicted to be an OMP by sixteen of the nineteen genomes analyzed from both Lyme disease and relapsing fever species, suggesting that it is likely an OMP in all genomes and there were three genomes with false negative predictions (Fig. 5). The BB0405 and BB0406 orthologs were predicted to constitute clusters of candidate OMPs specific for Lyme disease causing spirochetes. One BB0405 and two BB0406 orthologs were predicted not to be OMPs, suggesting these are false negative predictions since 11/12 and 10/ 12 Lyme disease associated genomes predicted BB0405 and BB0406 to be an OMP, respectively (Fig. 5). While relapsing fever spirochetes do encode BB0405 and BB0406 orthologs, those protein sequences did not cluster with the orthologs from the Lyme disease spirochetes according to the parameters used in this study. Collectively, these data provide a group of candidate OMPs that are conserved among various species of Borrelia spirochetes and can be examined as potential OMPs and virulence factors in future studies.

\section{Discussion}

Given that Lyme disease and relapsing fever spirochetes are extracellular pathogens, the surface of these spirochetes and the proteins localized to their OM provide the interface between these pathogens and their various hosts during infection. It also has been established that humoral immunity provides protection against these infections; therefore, borrelial surface proteins have been the target of much study with regards to identifying new vaccine targets. To date, most vaccine studies have focused on the immunogenic surface lipoproteins [12, 25, 88-93] with much less emphasis being placed on integral OMPs localized to the surface of the organism. This is due in part to the fact that surface lipoproteins are highly immunogenic and highly abundant, which has made lipoproteins much easier to identify and characterize than the borrelial OMPs. In this study, we sought to identify novel OMPs from Borrelia. Given that computer-based algorithms do not always accurately predict protein structure, we employed a consensus strategy in which we relied on six different algorithms that predict both OM localization and $\beta$-barrel conformation to identify candidate borrelial OMPs [58-63]. By using this stratified consensus approach, we were able to prioritize candidate OMPs based on the number of programs predicting that a specific sequence encoded a novel OMP. We curated our list by eliminating lipoproteins using a lipoprotein prediction algorithm specific for spirochetes [55] and proteins containing transmembrane domains $[56,57]$ that are indicative of inner membrane proteins. Moreover, we only accepted sequences with an $\mathrm{N}$-terminal signal peptide as would be required for translocation across the bacterial inner membrane, and we again instituted a consensus approach using four different programs to predict signal peptides [64-67]. Importantly, we identified several known borrelial OMPs by the computational framework utilized including 
BamA, BesC, P66, and DipA, and, of the wellcharacterized OMPs identified thus far, only the known borrelial OMP P13 was not identified in our study. In a previous study, chromosomally encoded proteins from all sequenced bacterial genomes including the Borrelia spirochetes were analyzed by the TMBB algorithm which aims to identify $\beta$-barrel, OMPs [94]. Using this single method, 26 candidate B. burgdorferi B31 OMPs were identified of which eight were orthologous to nonOMPs. The study presented herein, however, identified 41 candidate OMPs further supporting the notion that the consensus approach utilized in these studies is an improvement from relying on a single algorithm.

Notably, we were able to further prioritize our list of candidate OMPs by examining and comparing the output generated from the chromosomes of nineteen different Lyme disease and relapsing fever organisms. With this approach, candidate OMPs could be further verified by the overall likelihood that the sequence was predicted to be an OMP in numerous other related borrelial organisms. In fact, potential false-positive or falsenegative predictions in a single spirochetal species or strain can easily be identified by comparing the OMP predictions for proteins in the same cluster from many different organisms as outlined here. Furthermore, this more global approach will allow future studies to focus on sequences predicted to be OMPs in numerous species that are considered viable vaccine candidates based on their overall sequence homology and tendency to cluster together according to the algorithm utilized in this study. The cluster analysis demonstrated that there is a large group of predicted OMPs that are shared among the genomes of all currently sequenced Borrelia spp. analyzed (Fig. 5, Group C), which potentially represent vaccine candidates that could protect against both Lyme disease and relapsing-fever infections. This is an important addition that could not only enhance vaccine development for various spirochete diseases, but this system could also be used for other groups of human pathogens given that one of the major caveats in vaccine development has been generating protective immune responses against multiple strains or species.

While it is likely that some of the candidates identified using the computational algorithm outlined herein are not OMPs, the physicochemical data provided for BB0405, BB0406, and BB0838 provide a robust proof of principle that the algorithm can accurately identify novel OMPs. Interestingly, a larger domain of the C-terminal region of BB0838 was protected from degradation when organisms were treated with trypsin as compared to proteinase $\mathrm{K}$. This type of proteolysis data would be entirely consistent with a large extracellular loop that contains a trypsin susceptible lysine or arginine residue but is otherwise fully susceptible to proteinase $\mathrm{K}$ degradation.
Consistent with this notion, the B. burgdorferi OMP P66 also has been shown in previous studies to be partially sensitive to both proteinase $\mathrm{K}$ and trypsin with a lysine residue in a surface loop that is uniquely susceptible to trypsin [51]. Interestingly, $b b 0838$ was found to be cotranscribed with $u v r A$ and $u v r B$. UvrA and UvrB along with UvrC and UvrD are members of the nucleotide excision repair (NER) pathway which was previously shown to be the only borrelial DNA repair pathway that functions to repair DNA in response to UV light damage $[73,74]$. In fact, $B$. burgdorferi spirochetes appear to have a reduced number of DNA repair enzymes $[11,20]$. Why a potential borrelial OMP such as BB0838 would be co-expressed with two components of the NER pathway is unclear. It is worth noting, however, that this gene arrangement and genomic organization was conserved among all Lyme disease- and relapsing fevercausing spirochetes examined. This conservation in gene organization and, by correlation, co-expression pattern of $u v r A B$ and $b b 0838$ and its various orthologs suggests this happened prior to the divergence of the various Borrelia spp. Whether BB0838 can incorporate into liposomes and/or forms a pore remains to be determined. Such experiments with BB0838 could not be performed due to the large size of the full-length native protein and our inability to generate a full-length recombinant protein that was not lethal when expressed in E. coli.

BB0406 also was observed to be a novel OMP that had not previously been identified from $B$. burgdorferi or any other Borrelia spp. to date. As previously suggested, BB0405 was confirmed to be a surface-exposed OMP $[22,39]$. While we demonstrated that BB0405 and BB0406 are OM-localized and capable of forming pores, BB0406 was found to be resistant to proteinase $\mathrm{K}$ degradation. Complete and partial resistance to protease has been reported for many other bacterial OMPs [30, 39, 95-98], so it was not entirely surprising that a borrelial OMP also is protease resistant. Given that we have now shown that BB0406 is a potential porin, it seems most likely BB0406 has either very little surface exposure or the protein is possibly protected from degradation by interacting with other surface OMPs or the abundant surface lipoproteins as was previously shown for the known OMP P66 [99]. Borreliae are known to have a relatively small genome as compared to other bacterial organisms and are thus dependent on the uptake of nutrients from the host environment. This highlights the importance of proteins such as porins for the survival of the spirochete throughout the organism's life cycle. Yet, a limited number of porins have been identified in $B$. burgdorferi $[41,50,100]$ despite the observation that in black lipid bilayer experiments using borrelial OM fractions there are numerous pore-forming proteins that have not been identified [101]. While BB0405 and 
BB0406 do form pores, we have not shown that these proteins form $\beta$-barrels as was predicted by the computer algorithms utilized in this study. Crystal structures will need to be resolved in order to definitively determine whether these proteins are $\beta$-barrels as predicted by the algorithm. However, recent reports have examined the structural conformation of both the $B$. afzelii BB0405 ortholog (BaPKo_0422) [102, 103] and the $B$. garinii BB0406 ortholog (BG_0408) using small-angle Xray scattering [103]. Notably, in these reports, it was demonstrated that both proteins form structures entirely consistent with an 8-stranded $\beta$-barrel further supporting the notion that BB0405 and BB0406 fold into $\beta$ barrels in the borrelial OM.

Among previously characterized pore-forming OMPs in $B$ burgdorferi, P13 and P66 are both known to be immunogenic and P66 has been shown to be at least partially protective in mice challenged with $B$. burgdorferi B31 [104-106]. Prior studies have shown that OMPs $\mathrm{P} 66$ and $\mathrm{BesC}$ are also required for establishing infection in mice $[33,107]$. Along these lines, we also previously observed that antibodies recognizing the putative OMP BB0405 were bactericidal and that nonhuman primates infected with $B$. burgdorferi elicit a specific antibody response against BB0405 [22]. In other studies, we also have determined that a mutant $B$. burgdorferi strain lacking BB0405 and BB0406 is unable to establish an infection in mice, suggesting that one or both of these proteins is also essential for mammalian infection (Shrestha, Kenedy, and Akins, unpublished observations). Whether the inability of the BB0405/406 mutant to infect mice is dependent on the porin function of these proteins is unknown at this time. Notably, BG0407 the B. garinii BB0405 ortholog and BAPK0422 the $B$. afzelii BB0405 orthlolg have both been shown to bind human Factor $\mathrm{H}[102,108]$. Binding of Factor $\mathrm{H}$ by bacteria inhibits the alternative pathway of complement and is a method of immune evasion for pathogenic organisms. Whether B. burgdorferi BB0405 also binds Factor $\mathrm{H}$ is unknown at this time. BB0838 also may play an important role in the infectious life cycle of $B$. burgdorferi. When global transposon mutagenesis of $B$. burgdorferi was performed by Norris and colleagues, no transposon insertions were identified within the $b b 0838$ gene [109, $110]$, suggesting it is an essential protein.

\section{Conclusions}

The computational and bioinformatics studies presented have identified novel OMPs from B. burgdorferi (BB0838 and BB0406) and confirmed that BB0405 also is a $B$. burgdorferi OMP. Furthermore, BB0405 and BB0406 were shown to have pore forming properties, suggesting they may play a role in allowing Borrelia spp. to sample and respond to environmental changes. In addition to a better catalog of candidate OMPs from various borrelial species, the computational framework utilized here could also help to identify new vaccine candidates for future studies. As it relates to vaccine-development, the overall clustering observed in Fig. 5 is provocative and points out specific candidate OMPs that could be targeted specifically for future Lyme disease or relapsing fever vaccine studies. Most important, however, is the fact that it may now be possible to identify potential vaccine candidates that could target both of these important human diseases with a single or multi-subunit vaccine consisting of OMPs shared by both groups. Apart from this applied aspect of vaccine development, basic mechanisms of molecular pathogenesis for this wide array of spirochetes could also be revealed in the various OMP protein clusters, which could imply functional specialization of specific OMPs that have evolved to support specific activities by Lyme-disease or relapsing-fever spirochetes. Further studies will be required to delineate among the proteins identified as to which are actual OMPs and which may be false positives. Finally, while the focus of our study was limited to Borrelia spp., it seems self-evident that a similar strategy could be used to identify OMPs from bacteria other than spirochetes to identify new vaccine targets for many different human diseases.

\section{Methods}

Computational framework for identifying candidate Borrelia outer membrane proteins (OMP)

Candidate OMPs were predicted according to the methods outlined in Fig. 1 and server URLs are listed in Additional file 5: Table S4. A summary of the servers utilized in this study was outlined previously [54]. The Borrelia genomes examined in the study are listed in Table 2 along with accession numbers. First, protein sequences from each open reading frame on each Borrelia chromosome was analyzed to determine if the protein was predicted to be a lipoprotein using the SpLip algorithm which was developed to specifically identify the unique characteristics of spirochaetal lipoproteins and was kindly provided by the authors [55]. Next, sequences were analyzed to determine if the protein was predicted to contain transmembrane $\alpha$-helices by the Phobius server [56] and the TMHMM server [57]. Outer membrane (OM) localization was next predicted by CELLO [58] and PSORTb 3.0 [59]. The following servers were utilized to predict $\beta$-barrel conformation: HHOMP [60], TMBETADISC-AAC [61], PRED-TMBB [62, 111], and BOMP [63]. After all sequences were examined by the above algorithms, a candidate OMP list was generated according to the following steps: (1) any protein predicted to be a lipoprotein was discarded, (2) any protein predicted to contain transmembrane $\alpha$-helices by either 
Phobius or TMHMM servers were discarded, (3) proteins were retained if they were predicted to be OMlocalized by either CELLO or pSORTb 3.0, and (4) proteins were retained if they were predicted to be a $\beta$ barrel by at least one of the four or two of the four $\beta$ barrel prediction programs depending on if the sequence was predicted to be OM-localized by two or one of the OM-localization programs, respectively. The remaining proteins were manually analyzed to remove any proteins orthologous to proteins that are not OMPs (i.e., proteins annotated to be orthologous to characterized cytoplasmic, inner membrane, or periplasmic proteins or any lipoproteins). Furthermore, the remaining sequences were subjected to analysis for an $\mathrm{N}$-terminal signal peptide by SignalP 3.0 [64], PrediSi [65]), Signal-CF [66], and manually inspected for signal sequences using hydrophilicity plots according to the methods of Kyte and Doolittle [67]. Sequences were only retained if the protein was predicted by at least one signal peptide prediction program to have a $\mathrm{N}$-terminal signal peptide. Finally, candidate OMPs were grouped by the number of programs predicting OM localization and $\beta$-barrel conformation. Proteins were removed from the candidate OMP list if the sequence was not predicted to be OM localized and have $\beta$-barrel conformation by three of the following six algorithims: CELLO, pSORTb, HHOMP, TMBETADISC-AAC, PRED-TMBB, and BOMP.

To identify clusters of orthologous sequences for predicted OMPs in each genome, the protein sequences were clustered using CD-hit [86] with cut-off parameters for percent identity and percent length equal to .50 and .80 , respectively. The protein clusters were merged with the outer membrane predictions in $\mathrm{R}$ to create a heatmap using the heatmap. 2 from the gplots package [87]. Protein sequences of less than 60 amino acids were not included in the heat map analysis.

\section{RNA Isolation and Reverse Transcriptase-PCR}

For RNA isolation, B. burgdorferi B31 cells $\left(3 \times 10^{9}\right)$ were pelleted at $5,800 \times g$ for $20 \mathrm{~min}$ at $4{ }^{\circ} \mathrm{C}$, and the pellet was resuspended in TRI Reagent (Sigma; St. Louis, $\mathrm{MO}$ ) before isolation of RNA according to the manufacturer's instructions. The final RNA pellet was resuspended in $30 \mu \mathrm{l}$ of RNase free water and was then DNase treated using the DNase I amplification grade kit from Sigma. cDNA was generated using the Phusion RT-PCR Kit (Thermo Fisher Scientific Inc, Waltham, MA) as well as specific primers listed in Table 3. For cDNA synthesis of the $u v r B, u v r A$, and $b b 0838$ operon, primers BB0838 RT 3' and UvrA RT 3' were used. For cDNA synthesis of the bb0404, bb0405, and bb0406 operon, primers BB0406 RT 3' and BB0405 RT 3' were used. Reactions were performed in both the presence of RT $(+R T)$ and in its absence (-RT). Subsequently, the cDNA was used for PCR analysis using PCR primer pairs listed in Table 3. In addition to cDNA, genomic DNA was included as a positive control for each reaction.

Table 3 Oligonucleotides utilized in the study

\begin{tabular}{|c|c|c|}
\hline Primer Name & Sequence $5^{\prime}-3^{\prime a}$ & Description \\
\hline BB0838 (2362) F & GCGGCTAGCTTATCTGATCCGGAAACTTITTA & Cloning bb0838 (2362) into the pET23a vector \\
\hline BB0838 R & GCGCTCGAGTCTATTAATAATAAACTCGTAGTTT & Cloning bb0838 (2362) into the pET23a vector \\
\hline BB0405 F & GCGGCTAGCTCCAAAAGCAAAAGTATGACTG & Cloning bb0405 into the pET23a vector \\
\hline BB0405 R & GCGCTCGAGTATATATATTITTATAAAGCCTGTG & Cloning bb0405 into the pET23a vector \\
\hline BB0406 F & GCGGGATCCTCTIITGCATCTGACAATTATATG & Cloning bb0406 into the pET23a vector \\
\hline BB0406 R & GCGCTCGAGTGCAAATTTTATGAATCCAAATCC & Cloning bb0406 into the pET23a vector \\
\hline BB0838 RT 3' & ATCTITAGTAAGTCCATAAGTGAAATTIT & cDNA synthesis for uvrA-bb0838 PCR reaction \\
\hline UvrA RT $3^{\prime}$ & GAGCCACTCTTGCCAGATATTA & cDNA synthesis for uvrB-uvrA PCR reaction \\
\hline BB0406 RT 3' & AATTCTTATAACAGCGCCTATTCTCTCATA & cDNA synthesis for bb0405-bb0406 PCR reaction \\
\hline BB0405 RT 3' & CATAGTTGTTCCAATAGTAGCAACAGC & cDNA synthesis for bb0404-bb0405 PCR reaction \\
\hline UvrB PCR $5^{\prime}$ & GATTGTCTAAAAAAAAGCTTATTGATAAG & RT-PCR of uvrB-uvrA \\
\hline UvrA PCR 3' & TGGAATATCTACATCAACATIIITTAAATT & RT-PCR of uvrB-uvrA \\
\hline UvrA PCR $5^{\prime}$ & GTTTCTGGTATTCCTGAAGAGG & RT-PCR of uvrA-bb0838 \\
\hline BB0838 PCR 3' & CCAGATCCGGCAAGTCCC & RT-PCR of uvrA-bb0838 \\
\hline BB0404 PCR $5^{\prime}$ & ATTAATGGCCTAAAGTTAGCTTCAAAAAG & RT-PCR of bb0404-bb0405 \\
\hline BB0405 PCR 3' & GCTGTACTCTATTACCAAAGGCAA & RT-PCR of bb0404-bb0405 \\
\hline BB0405 PCR 5' & GTTGTGATGGGTGTAGATCTTCT & RT-PCR of bb0405-bb0406 \\
\hline BB0406 PCR 3' & AATTCTTATAACAGCGCCTATTCTCTCATA & RT-PCR of bb0405-bb0406 \\
\hline
\end{tabular}

${ }^{a}$ Restriction enzymes noted in bold 
Cloning, purification, and folding of candidate OMPs Candidate OMP DNA sequences including bb0405, bb0406, and bb0838 were amplified from B. burgdorferi B31 genomic DNA using primers listed in Table 3. The amplicons were subsequently digested and cloned into the NheI or BamHI and XhoI sites of pET23a (EMD Millipore, Billerica, MA). The constructs were transformed into the E. coli strain Rosetta 2 DE3 (EMD Millipore), and DNA sequencing was performed to verify that the sequence remained unaltered throughout the cloning process. Recombinant proteins were induced and purified using nickel-nitrilotriacetic acid agarose (Qiagen,Valencia, CA) as described previously [51]. Recombinant BB0405 and BB0406 were folded in DDM buffer [50 mM Tris, $100 \mathrm{mM} \mathrm{NaCl}$, dodecyl- $\beta$-D-maltopyranoside (DDM; Affymetrix, 14 Santa Clara, CA)] pH 7.6 for BB0405 (0.5 \% DDM) and pH 8.6 for BB0406 (2.0\% DDM) (pH and DDM concentrations were optimized for each protein) at $4{ }^{\circ} \mathrm{C}$ overnight, and the insoluble material was pelleted by centrifugation at 20,000 $\mathrm{x}$ $g$ for $30 \mathrm{~min}$ at $4{ }^{\circ} \mathrm{C}$.

\section{Immunoblotting and antibody production}

SDS-PAGE and immunoblotting procedures were performed as described elsewhere [39, 112]. Rat polyclonal antibodies specific for BB0405 and BB0406 were generated by Harlan Bioproducts for Science, Inc. (Madison, WI) and were used at a dilution of 1:1,000 or for enhanced chemiluminescence. P66, OspA, FlaB, BB0028, Skp, OppAIV, OmpA, and GST antibodies were described previously $[22,39,42,51,113]$. To generate antibodies directed against BB0838, a C-terminal BB0838 peptide corresponding to the final 18 amino acids of BB0838 $\left(E^{1129}-K^{1146}\right)$ was first synthesized by Thermo Fisher Scientific, and, subsequently, rabbit antisera was generated against the BB0838 C-terminal peptide (Thermo Fisher Scientific). For BB0838 immunoblots, rabbit anti-BB0838 peptide antibodies were affinity purified and used for immunoblotting at a concentration of $1: 10$.

\section{Triton $\mathrm{X}-114$ phase partitioning}

B. burgdorferi B31 whole-cell lysates were subjected to Triton X-114 phase partitioning as described elsewhere $[22,39,114,115]$ to examine the amphiphilic properties of native BB0838, BB0405, and BB0406. For BB0838, whole-cell lysates were first solubilized in $2 \%$ DDM in PBS for two hours at room temperature before being pelleted and beginning phase partitioning which was previously described [115]. The detergent- and aqueousenriched fractions were precipitated with acetone and subjected to SDS-PAGE and immunoblot using rabbit anti-BB0838 peptide antibody, rat anti-405, rat anti-406, rat anti-BB0028, or rat anti-Skp antibodies.

\section{Outer membrane preparation}

B. burgdorferi B31 OM and protoplasmic cylinder (PC) fractions were enriched as previously described [39]. Subsequently, the fractions were separated by SDSPAGE and immunoblotted with rabbit anti-BB0838, rat anti-BB405, or rat anti-BB406 antibodies to determine if these proteins are localized to the borrelial OM. Membranes were also immunoblotted with antibodies recognizing the known OMP P66 as well as the inner membrane lipoprotein OppAIV, which served a negative control for OM purity.

\section{Proteinase $\mathrm{K}$ and trypsin surface accessibility assays}

For proteinase $\mathrm{K}$ accessibility experiments, $2 \times 10^{8} \mathrm{~B}$. burgdorferi B31 cells were gently pelleted at $4,000 \times g$ for 4 min and washed three times in PBS (pH 7.4). The final pellet was resuspended in $1 \mathrm{ml}$ of PBS, and samples were aliquoted into $500 \mu \mathrm{l}$ reactions that were either treated or mock-treated with $200 \mu \mathrm{g}$ PK (PK; Sigma) for one hour at room temperature. Phenylmethylsulfonylfluoride (0.4 mM; Sigma) was added to each sample to stop the PK reaction, and the samples were pelleted at $10,000 \times g$ for $10 \mathrm{~min}$. The final pellets were prepared for SDS-PAGE and immunoblot analysis with anti-BB0838, anti-BB0405, or anti-BB0406 antibodies. Equivalent membranes were also subjected to immunoblot with antibodies to OspA or FlaB for surface and sub-surface controls, respectively. Trypsin digest assays were performed as described above for PK experiments except cells were incubated with $200 \mu \mathrm{g} / \mathrm{ml}$ trypsin which was resuspended in $0.001 \mathrm{~N} \mathrm{HCl}$. As controls, membranes were also immunoblotted with P66 and FlaB antibodies. Relative mobility (rf) was calculated in duplicate for full length and digested BB0838 to determine the molecular weight.

\section{Liposome incorporation assay}

Large unilamellar vesicles (LUVs) were prepared as described [51, 115] using a mixture of 1-palmitoyl-2oleoyl-sn-glycero-3-phosphocholine and 1-palmitoyl- 2oleoyl-sn-glycero-3-[phospho-L-serine] (sodium salt) (Avanti Polar Lipids, Inc., Alabaster, AL), (70:30 mol \%, respectively) to mimic the B. burgdorferi B31 OM phospholipid content [82]. For liposome incorporation assays, which were also decribed elsewhere [51, 115], recombinant BB0405 (400 ng) or BB0406 (400 ng) folded in DDM buffer were added to approximately $750 \mu \mathrm{g}$ of LUVs in $50 \mathrm{mM}$ Tris, $100 \mathrm{mM} \mathrm{NaCl}$ buffer $\mathrm{pH} 7.6$ in $200 \mu \mathrm{l}$ reactions and incubated at room temperature for $1 \mathrm{~h}$. Subsequently, $200 \mathrm{mg}$ of sucrose was added to each reaction, and $250 \mu \mathrm{l}$ of $40 \%$ sucrose followed by $300 \mu \mathrm{l}$ of $6 \%$ sucrose dissolved $50 \mathrm{mM}$ Tris, $100 \mathrm{mM} \mathrm{NaCl}$ buffer $\mathrm{pH} 7.6$ were then layered on top of the samples in ultracentrifuge tubes. The discontinuous sucrose gradients were centrifuged at $90,000 \mathrm{rpm}$ for $1 \mathrm{~h}$ at $4{ }^{\circ} \mathrm{C}$ in a 
fixed angle TLA-120.2 rotor (Beckman Coulter, Brea, CA). After centrifugations, gradient fractions of equal volume were carefully collected from the top, middle, and bottom layers of the tube. Top and bottom fractions were analyzed by SDS-PAGE and immunoblot analysis with rat anti-BB0405 or rat anti-BB0406 antibodies. Control experiments were performed using recombinant E. coli OmpA protein folded in DDM buffer and recombinant GST protein.

\section{Pore formation assay}

Pore formation assays were described elsewhere [116, 117]. Briefly, dried lipids were resuspended in hepes buffer containing $3 \mathrm{mM}$ terbium chloride and $9 \mathrm{mM}$ 2,6-pyridinedicarboxlic acid (DPA) before liposome preparation as described previously [116]. $\mathrm{Tb}(\mathrm{DPA})_{3}^{3-}$ loaded liposomes were diluted in buffer containing $50 \mathrm{mM}$ Tris (pH 7.5), $100 \mathrm{mM} \mathrm{NaCl}$, and $5 \mathrm{mM}$ EDTA to a concentration of $100 \mu \mathrm{M}$ total lipids. The sample was incubated at $25{ }^{\circ} \mathrm{C}$ for $5 \mathrm{~min}$, and the net initial emission intensity $\left(F_{0}\right)$ was determined. Next, recombinant proteins including BB0405, BB0406, P66, E. coli OmpA, or E. coli OmpF (100 nM final concentration) were added to the liposome suspension and incubated $37^{\circ} \mathrm{C}$ for $30 \mathrm{~min}$. Samples were then re-equilibrated to $25{ }^{\circ} \mathrm{C}$, and the final net emission intensity $\left(F_{\mathrm{f}}\right)$ of each reaction was determined after subtracting the blank and correcting for dilutions. The fraction of $\mathrm{Tb}(\mathrm{DPA})_{3}^{3-}$ quenched was estimated using $F_{f} / F_{0}$.

\section{Additional files}

Additional file 1: Table S1. Predictions for all ORFs. Lipoprotein, trans-membrane a-helix, cellular localization, and $\beta$-barrel prediction data collected for all ORFs for all genomes analyzed. (XLS $5022 \mathrm{~kb}$ )

Additional file 2: Table S2. Candidate OMPs from various Borrelia genomes. List of proteins predicted to be OMPs for all genomes analyzed. (XLS $311 \mathrm{~kb}$ )

Additional file 3: Table S3. Orthologous clusters. List of predicted orthologous clusters utilized to generate heat maps. (XLSX $667 \mathrm{~kb}$ )

Additional file 4: Figure S1. Orthologous clusters and OMP prediction heat map. Orthologous clusters from each borrelial genome organized in unique columns as a heat map. Green blocks in each column indicate Borrelia proteins predicted to be OMPs, while Borrelia proteins not passing all OMP prediction filters are represented by red blocks. Black blocks indicate an orthologous protein was not identified in a given borrelial genome. These data were then subjected to a two-way hierarchical clustering examining orthologs (column blocks) by genomes (row blocks). Unique cluster IDs are shown at the bottom of the figure and correspond to the cluster numbers listed in Additional file 5: Table S4. Genomes analyzed are listed at right. (PDF $18 \mathrm{~kb}$ )

Additional file 5: Table S4. Servers utilized in this study. List of all servers utilized in the study as well as URLs and references for each server. (DOCX $14 \mathrm{~kb}$ )

\section{Acknowledgments}

We would like to thank Dr. Amit Luthra for assistance in developing a workflow for OMP prediction.

\section{Funding}

This work was supported by grants Al059373 from NIH/NIAID to DRA and Al-29735 to JDR and by funds from Connecticut Children's Medical Center (JDR).

\section{Availability of data and materials}

All data supporting our findings are present within the manuscript and in additional files. All data will be made available upon request.

\section{Authors' contributions}

MK designed and/or carried out all experiments and prepared the initial draft of the manuscript. ES and DD carried out the bioinformatics analysis. BS carried out experiments for BB0405 and BB0406. AA performed the pore formation analysis. $\mathrm{HH}$ performed RT-PCR for the b60404, b60405, and bb0406 operon and performed PK and OM experiments for BB0405 and BB0406. DD and JR participated in the design of the studies and provided intellectual input throughout the studies and editing for the final draft of the manuscript. DA conceived the study and provided assistance in drafting the manuscript. All authors read and approved the final manuscript.

\section{Competing interests}

The authors declare that they have no competing interests.

\section{Consent for publication}

Not applicable.

Ethics approval and consent to participate Not applicable.

\section{Author details}

'Department of Microbiology and Immunology, University of Oklahoma Health Sciences Center, Oklahoma City, Oklahoma 73104, USA. ²Department of Medicine, University of Connecticut Health Center, Farmington,

Connecticut 06030, USA. ${ }^{3}$ Department of Pediatrics, University of Connecticut Health Center, Farmington, Connecticut 06030, USA. ${ }^{4}$ Department of Genetics and Genomic Science, University of Connecticut Health Center, Farmington, Connecticut 06030, USA. ${ }^{5}$ Department of Immunology, University of Connecticut Health Center, Farmington, Connecticut 06030, USA. ${ }^{6}$ Department of Molecular Biology and Biophysics, University of Connecticut Health Center, Farmington, Connecticut 06030, USA.

Received: 10 February 2016 Accepted: 2 July 2016

Published online: 11 July 2016

\section{References}

1. Steere AC, Coburn J, Glickstein L. The emergence of Lyme disease. J Clin Invest. 2004;113:1093-101.

2. Schwan TG, Piesman J. Vector interactions and molecular adaptations of Lyme disease and relapsing fever spirochetes associated with transmission by ticks. Emerg Infect Dis. 2002;8:115-21.

3. Collares-Pereira M, Couceiro S, Franca I, Kurtenbach K, Schafer SM, Vitorino L, Goncalves L, Baptista S, Vieira ML, Cunha C. First isolation of Borrelia Iusitaniae from a human patient. J Clin Microbiol. 2004;42:1316-8.

4. Diza E, Papa A, Vezyri E, Tsounis S, Milonas I, Antoniadis A. Borrelia valaisiana in cerebrospinal fluid. Emerg Infect Dis. 2004;10:1692-3.

5. Fingerle V, Schulte-Spechtel UC, Ruzic-Sabljic E, Leonhard S, Hofmann H, Weber K, Pfister K, Strle F, Wilske B. Epidemiological aspects and molecular characterization of Borrelia burgdorferi s.l. from southern Germany with special respect to the new species Borrelia spielmanii sp. nov. Int J Med Microbiol. 2008;298:279-90.

6. Rudenko N, Golovchenko M, Ruzek D, Piskunova N, Mallatova N, Grubhoffer L. Molecular detection of Borrelia bissettii DNA in serum samples from patients in the Czech Republic with suspected borreliosis. FEMS Microbiol Lett. 2009;292:274-81.

7. Stanek G, Reiter M. The expanding Lyme Borrelia complex-clinical significance of genomic species? Clin Microbiol Infect. 2011;17:487-93. 
8. Barbour AG, Guo BP. Pathogenesis of Relapsing Fever. In: Samuels DS, Radolf JD, editors. Borrelia: Molecular biology, host interaction and pathogenesis. Norfolk, UK: Caister Academic Press; 2010. p. 333-58.

9. Piesman J, Schwan TG. Ecology of Borreliae and Their Arthropod Vectors. In: Samuels DS, Radolf JD, editors. Borrelia: Molecular biology, host interaction and pathogenesis. Norfolk, UK: Caister Academic Press; 2010. p. 251-78.

10. Takayama K, Rothenberg RJ, Barbour AG. Absence of lipopolysaccharide in the Lyme disease spirochete, Borrelia burgdorferi. Infect Immun. 1987;55: 2311-3

11. Fraser CM, Casjens S, Huang WM, Sutton GG, Clayton R, Lathigra R, White $O$, Ketchum KA, Dodson R, Hickey EK, Gwinn M, Dougherty B, Tomb J-F, Fleischmann RD, Richardson D, Peterson J, Kerlavage AR, Quackenbush J, Salzberg S, Hanson M, van Vugt R, Palmer N, Adams MD, Gocayne J, Weidman J, Utterback T, Watthey L, McDonald L, Artiach P, Bowman C, Garland S, Fujii C, Cotton MD, Horst K, Roberts K, Hatch B, Smith HO, Venter JC. Genomic sequence of a Lyme disease spirochaete, Borrelia burgdorferi. Nature. 1997:390:580-6.

12. Brandt ME, Riley BS, Radolf JD, Norgard MV. Immunogenic integral membrane proteins of Borrelia burgdorferi are lipoproteins. Infect Immun. 1990;58:983-91.

13. Fuchs R, Jauris S, Lottspeich F, Preac-Mursic V, Wilske B, Soutschek E. Molecular analysis and expression of a Borrelia burgdorferi gene encoding a 22 kDa protein (pC) in Escherichia coli. Mol Microbiol. 1992;6:503-9.

14. Lam TT, Nguyen TPK, Montgomery RR, Kantor FS, Fikrig E, Flavell RA. Outer surface proteins $\mathrm{E}$ and $\mathrm{F}$ of Borrelia burgdorferi, the agent of Lyme disease. Infect Immun. 1994;62:290-8.

15. Howe TR, Mayer LW, Barbour AG. A single recombinant plasmid expressing two major outer surface proteins of the Lyme disease spirochete. Science. 1985;227:645-6.

16. Norris SJ, Carter CJ, Howell JK, Barbour AG. Low-passage-associated proteins of Borrelia burgdorferi B31: characterization and molecular cloning of OspD, a surface-exposed, plasmid-encoded lipoprotein. Infect Immun. 1992;60: 4662-72.

17. Zhang JR, Hardham JM, Barbour AG, Norris SJ. Antigenic variation in Lyme disease Borreliae by promiscuous recombination of Vmp-like sequence cassettes. Cell. 1997:89:275-85.

18. Probert WS, Johnson BJB. Identification of a $47 \mathrm{kDa}$ fibronectin-binding protein expressed by Borrelia burgdorferi isolate B31. Mol Microbiol. 1998; 30:1003-15.

19. Guo B, Norris SJ, Rosenberg LC, Hook M. Adherence of Borrelia burgdorferi to the proteoglycan decorin. Infect Immun. 1995;63:3467-72.

20. Casjens S, Palmer N, van Vugt R, Huang WM, Stevenson B, Rosa P, Lathigra R, Sutton G, Peterson J, Dodson RJ, Haft D, Hickey E, Gwinn M, White O, Fraser CM. A bacterial genome in flux: the twelve linear and nine circular extrachromosomal DNAs in an infectious isolate of the Lyme disease spirochete Borrelia burgdorferi. Mol Microbiol. 2000;35:490-516.

21. Wallich R, Pattathu J, Kitiratschky V, Brenner C, Zipfel PF, Brade V, Simon MM, Kraiczy P. Identification and functional characterization of complement regulator-acquiring surface protein 1 of the Lyme disease spirochetes Borrelia afzelii and Borrelia garinii. Infect Immun. 2005;73:2351-9.

22. Brooks CS, Vuppala SR, Jett AM, Akins DR. Identification of Borrelia burgdorferi outer surface proteins. Infect Immun. 2006;74:296-304.

23. Kenedy MR, Lenhart TR, Akins DR. The role of Borrelia burgdorferi outer surface proteins. FEMS Immunol Med Microbiol. 2012;66:1-19.

24. Schwan TG, Piesman J, Golde WT, Dolan MC, Rosa PA. Induction of an outer surface protein on Borrelia burgdorferi during tick feeding. Proc Natl Acad Sci U S A. 1995;92:2909-13.

25. de Silva AM, Telford SR, Brunet LR, Barthold SW, Fikrig E. Borrelia burgdorferi OspA is an arthropod-specific transmission-blocking Lyme disease vaccine. J Exp Med. 1996;183:271-5.

26. Hefty PS, Jolliff SE, Caimano MJ, Wikel SK, Radolf JD, Akins DR. Regulation of OspE-related, OspF-related, and Elp lipoproteins of Borrelia burgdorferi strain 297 by mammalian host-specific signals. Infect Immun. 2001;69:3618-27.

27. Ojaimi C, Brooks C, Casjens S, Rosa P, Elias A, Barbour A, Jasinskas A, Benach J, Katona L, Radolf J, Caimano M, Skare J, Swingle K, Akins D, Schwartz I. Profiling of temperature-induced changes in Borrelia burgdorferi gene expression by using whole genome arrays. Infect Immun. 2003;71:1689-705.

28. Brooks CS, Hefty PS, Jolliff SE, Akins DR. Global analysis of Borrelia burgdorferi genes regulated by mammalian host-specific signals. Infect Immun. 2003;71: 3371-83.
29. Fairman JW, Noinaj N, Buchanan SK. The structural biology of beta-barrel membrane proteins: a summary of recent reports. Curr Opin Struct Biol. 2011;21:523-31.

30. Tommassen J. Assembly of outer-membrane proteins in bacteria and mitochondria. Microbiology. 2010;156:2587-96.

31. Lugtenberg B, van Alphen L. Molecular architecture and functioning of the outer membrane of Escherichia coli and other Gram-negative bacteria. Biochim Biophys Acta. 1983;737:51-115.

32. Radolf JD, Bourell KW, Akins DR, Brusca JS, Norgard MV. Analysis of Borrelia burgdorferi membrane architecture by freeze-fracture electron microscopy. J Bacteriol. 1994;176:21-31.

33. Bunikis I, Denker K, Ostberg Y, Andersen C, Benz R, Bergstrom S. An RND-type efflux system in Borrelia burgdorferi is involved in virulence and resistance to antimicrobial compounds. PLoS Pathog. 2008;4:e1000009.

34. Coburn J, Chege W, Magoun L, Bodary SC, Leong JM. Characterization of a candidate Borrelia burgdorferi beta(3)-chain integrin ligand identified using a phage display library. Mol Microbiol. 1999;34:926-40.

35. Antonara S, Chafel RM, LaFrance M, Coburn J. Borrelia burgdorferi adhesins identified using in vivo phage display. Mol Microbiol. 2007;66:262-76.

36. Defoe G, Coburn J. Delineation of Borrelia burgdorferi p66 sequences required for integrin alpha(IIb)beta(3) recognition. Infect Immun. 2001;69: 3455-9.

37. Coburn J, Cugini C. Targeted mutation of the outer membrane protein P66 disrupts attachment of the Lyme disease agent, Borrelia burgdorferi, to integrin alphavbeta3. Proc Natl Acad Sci U S A. 2003;100:7301-6.

38. Thein M, Bunikis I, Denker K, Larsson C, Cutler S, Drancourt M, Schwan TG, Mentele R, Lottspeich F, Bergstrom S, Benz R. Oms38 is the first identified pore-forming protein in the outer membrane of relapsing fever spirochetes. J Bacteriol. 2008:190:7035-42.

39. Lenhart TR, Akins DR. Borrelia burgdorferi locus BB0795 encodes a BamA orthologue required for growth and efficient localization of outer membrane proteins. Mol Microbiol. 2010;75:692-795

40. Barcena-Uribarri I, Thein M, Sacher A, Bunikis I, Bonde M, Bergstrom S, Benz R. P66 porins are present in both Lyme disease and relapsing fever spirochetes: A comparison of the biophysical properties of P66 porins from six Borrelia species. Biochim Biophys Acta. 1798;2010:1197-203.

41. Thein M, Bonde M, Bunikis I, Denker K, Sickmann A, Bergstrom S, Benz R. DipA, a pore-forming protein in the outer membrane of Lyme disease spirochetes exhibits specificity for the permeation of dicarboxylates. PLoS One. 2012;7:e36523.

42. Dunn JP, Kenedy MR, Iqbal H, Akins DR. Characterization of the beta-barrel assembly machine accessory lipoproteins from Borrelia burgdorferi. BMC Microbiol. 2015;15:70.

43. Bunikis J, Noppa L, Bergstrom S. Molecular analysis of a 66-kDa protein associated with the outer membrane of Lyme disease Borrelia. FEMS Microbiol Lett. 1995:131:139-45.

44. Probert WS, Allsup KM, LeFebvre RB. Identification and characterization of a surface-exposed 66-kilodalton protein from Borrelia burgdorferi. Infect Immun. 1995;63:1933-9.

45. Noppa L, Ostberg Y, Lavrinovicha M, Bergstrom S. P13, an integral membrane protein of Borrelia burgdorferi, is C-terminally processed and contains surface-exposed domains. Infect Immun. 2001;69:3323-34.

46. Yang X, Lenhart TR, Kariu T, Anguita J, Akins DR, Pal U. Characterization of unique regions of Borrelia burgdorferi surface-located membrane protein 1. Infect Immun. 2010;78:4477-87.

47. Parveen $\mathrm{N}$, Leong J. Identification of a candidate glycosaminoglycanbinding adhesin of the Lyme disease spirochete Borrelia burgdorferi. Mol Microbiol. 2000;35:1220-34.

48. Russell TM, Johnson BJ. Lyme disease spirochaetes possess an aggrecanbinding protease with aggrecanase activity. Mol Microbiol. 2013;90:228-40.

49. Wood E, Tamborero S, Mingarro I, Esteve-Gassent MD. BB0172, a Borrelia burgdorferi outer membrane protein that binds integrin a3 $\beta 1$. J Bacteriol. 2013:195:3320-30.

50. Skare JT, Mirzabekov TA, Shang ES, Blanco DR, Erdjument-bromage $H$, Bunikis J, Bergstrom S, Tempst P, Kagan BL, Miller JN, Lovett MA. The Oms66 (p66) protein is a Borrelia burgdorferi porin. Infect Immun. 1997;65:3654-61.

51. Kenedy MR, Luthra A, Anand A, Dunn JP, Radolf JD, Akins DR. Structural modeling and physicochemical characterization provide evidence that P66 forms a $\beta$-barrel in the Borrelia burgdorferi outer membrane. J Bacteriol. 2014;196:859-72. 
52. Barcena-Uribarri I, Thein M, Barbot M, Sans-Serramitjana E, Bonde M, Mentele R, Lottspeich F, Bergstrom S, Benz R. Study of the protein complex, pore diameter, and pore-forming activity of the Borrelia burgdorferi P13 porin. J Biol Chem. 2014;289:18614-24.

53. Yang X, Promnares K, Qin J, He M, Shroder DY, Kariu T, Wang Y, Pal U. Characterization of Multiprotein Complexes of the Borrelia burgdorferi Outer Membrane Vesicles. J Proteome Res. 2011;10:4556-66.

54. Cox DL, Luthra A, Dunham-Ems S, Desrosiers DC, Salazar JC, Caimano MJ, Radolf JD. Surface immunolabeling and consensus computational framework to identify candidate rare outer membrane proteins of Treponema pallidum. Infect Immun. 2010;78:5178-94.

55. Setubal JC, Reis M, Matsunaga J, Haake DA. Lipoprotein computational prediction in spirochaetal genomes. Microbiology. 2006;152:113-21.

56. Kall L, Krogh A, Sonnhammer EL. A combined transmembrane topology and signal peptide prediction method. J Mol Biol. 2004;338: 1027-36.

57. Krogh A, Larsson B, Von HG, Sonnhammer EL. Predicting transmembrane protein topology with a hidden Markov model: application to complete genomes. J Mol Biol. 2001;305:567-80.

58. Yu CS, Lin CJ, Hwang JK. Predicting subcellular localization of proteins for Gram-negative bacteria by support vector machines based on n-peptide compositions. Protein Sci. 2004;13:1402-6.

59. Yu NY, Wagner JR, Laird MR, Melli G, Rey S, Lo R, Dao P, Sahinalp SC, Ester M, Foster $\sqcup$, Brinkman FS. PSORTb 3.0: improved protein subcellular localization prediction with refined localization subcategories and predictive capabilities for all prokaryotes. Bioinformatics. 2010;26:1608-15.

60. Remmert M, Linke D, Lupas AN, Soding J. HHomp-prediction and classification of outer membrane proteins. Nucleic Acids Res. 2009;37:W446-51.

61. Ou YY, Gromiha MM, Chen SA, Suwa M. TMBETADISC-RBF: Discrimination of beta-barrel membrane proteins using RBF networks and PSSM profiles. Comput Biol Chem. 2008;32:227-31.

62. Bagos PG, Liakopoulos TD, Spyropoulos IC, Hamodrakas SJ. PRED-TMBB: a web server for predicting the topology of beta-barrel outer membrane proteins. Nucleic Acids Res. 2004;32:W400-4.

63. Berven FS, Flikka K, Jensen HB, Eidhammer I. BOMP: a program to predict integral beta-barrel outer membrane proteins encoded within genomes of Gram-negative bacteria. Nucleic Acids Res. 2004;32:W394-9.

64. Bendtsen JD, Nielsen H, von Heijne G, Brunak S. Improved prediction of signal peptides: SignalP 3.0. J Mol Biol. 2004;340:783-95.

65. Hiller K, Grote A, Scheer M, Munch R, Jahn D. PrediSi: prediction of signal peptides and their cleavage positions. Nucleic Acids Res. 2004;32:W375-9.

66. Chou KC, Shen HB. Signal-CF: a subsite-coupled and window-fusing approach for predicting signal peptides. Biochem Biophys Res Commun. 2007;357:633-40.

67. Kyte J, Doolittle RF. A simple method for displaying the hydropathic character of a protein. J Mol Biol. 1982;157:105-32.

68. Selkrig J, Mosbahi K, Webb CT, Belousoff MJ, Perry AJ, Wells TJ, Morris F, Leyton DL, Totsika M, Phan MD, Celik N, Kelly M, Oates C, Hartland EL, Robins-Browne RM, Ramarathinam SH, Purcell AW, Schembri MA, Strugnell RA, Henderson IR, Walker D, Lithgow T. Discovery of an archetypal protein transport system in bacterial outer membranes. Nat Struct Mol Biol. 2012;19: 506-10. S1.

69. Stegmeier JF, Gluck A, Sukumaran S, Mantele W, Andersen C. Characterisation of YtfM, a second member of the Omp85 family in Escherichia coli. Biol Chem. 2007;388:37-46.

70. Diaz-Mejia JJ, Babu M, Emili A. Computational and experimental approaches to chart the Escherichia coli cell-envelope-associated proteome and interactome. FEMS Microbiol Rev. 2009;33:66-97.

71. Babu M, Diaz-Mejia JJ, Vlasblom J, Gagarinova A, Phanse S, Graham C, Yousif F, Ding $H$, Xiong X, Nazarians-Armavil A, Alamgir M, Ali M, Pogoutse O, Pe'er A, Arnold R, Michaut M, Parkinson J, Golshani A, Whitfield C, Wodak SJ, Moreno-Hagelsieb G, Greenblatt JF, Emili A. Genetic interaction maps in Escherichia coli reveal functional crosstalk among cell envelope biogenesis pathways. PLoS Genet. 2011;7:e1002377.

72. Heinz E, Selkrig J, Belousoff M, Lithgow T: Evolution of the Translocation and Assembly Module (TAM). Genome Biol Evol. 2015;7:1628-43.

73. Sambir M, Ivanova LB, Bryksin AV, Godfrey HP, Cabello FC. Functional analysis of Borrelia burgdorferi uvrA in DNA damage protection. FEMS Microbiol Lett. 2011;317:172-80.
74. Hardy PO, Chaconas G. The nucleotide excision repair system of Borrelia burgdorferi is the sole pathway involved in repair of DNA damage by UV light. J Bacteriol. 2013;195:2220-31.

75. Wu T, McCandlish AC, Gronenberg LS, Chng SS, Silhavy TJ, Kahne D. Identification of a protein complex that assembles lipopolysaccharide in the outer membrane of Escherichia coli. Proc Natl Acad Sci U S A. 2006;103:11754-9.

76. Chng SS, Ruiz N, Chimalakonda G, Silhavy TJ, Kahne D. Characterization of the two-protein complex in Escherichia coli responsible for lipopolysaccharide assembly at the outer membrane. Proc Natl Acad Sci U S A. 2010;107:5363-8.

77. Zhang Y. I-TASSER server for protein 3D structure prediction. BMC Bioinformatics. 2008;9:40.

78. Roy A, Yang J, Zhang Y. COFACTOR: an accurate comparative algorithm for structure-based protein function annotation. Nucleic Acids Res. 2012:40:W471-7.

79. Roy A, Kucukural A, Zhang Y. I-TASSER: a unified platform for automated protein structure and function prediction. Nat Protoc. 2010; 5:725-38

80. Yang $Y$, Faraggi $E$, Zhao $H$, Zhou Y. Improving protein fold recognition and template-based modeling by employing probabilistic-based matching between predicted one-dimensional structural properties of query and corresponding native properties of templates. Bioinformatics. 2011; 27:2076-82.

81. Bordier C. Phase separation of integral membrane proteins in Triton X-114 solution. J Biol Chem. 1981;256:1604-7.

82. Belisle JT, Brandt ME, Radolf JD, Norgard MV. Fatty acids of Treponema pallidum and Borrelia burgdorferi lipoproteins. J Bacteriol. 1994; 176:2151-7.

83. Smith SG, Mahon V, Lambert MA, Fagan RP. A molecular Swiss army knife: OmpA structure, function and expression. FEMS Microbiol Lett. 2007;273:1-11.

84. Nikaido $\mathrm{H}$. Molecular basis of bacterial outer membrane permeability revisited. Microbiol Mol Biol Rev. 2003;67:593-656.

85. Anand A, Ledoyt M, Karanian C, Luthra A, Koszelak-Rosenblum M, Malkowski MG, Puthenveetil R, Vinogradova O, Radolf JD. Bipartite topology of Treponema pallidum Repeat Proteins C/D and I: outer membrane insertion, trimerization, and porin function require a c-terminal beta-barrel domain. J Biol Chem. 2015:290:12313-31.

86. Fu L, Niu B, Zhu Z, Wu S, Li W. CD-HIT: accelerated for clustering the nextgeneration sequencing data. Bioinformatics. 2012;28:3150-2.

87. R Core Team. R: A language and environment for statistical computing. Vienna, Austria: R Foundation for Statistical Computing; 2016. https:/www.R-project.org/.

88. Feng S, Hodzic E, Stevenson B, Barthold SW. Humoral immunity to Borrelia burgdorferi $\mathrm{N} 40$ decorin binding proteins during infection of laboratory mice. Infect Immun. 1998;66:2827-35.

89. Fikrig E, Barthold SW, Sun W, Feng W, Telford SR, Flavell RA. Borrelia burgdorferi p35 and p37 proteins, expressed in vivo, elicit protective immunity. Immunity. 1997;6:531-9.

90. Hanson MS, Cassatt DR, Guo BP, Patel NK, McCarthy MP, Dorward DW, Hook M. Active and passive immunity against Borrelia burgdorferi decorin binding protein A (DbpA) protects against infection. Infect Immun. 1998;66:2143-53.

91. Labandeira-Rey M, Baker EA, Skare JT. VraA (BBI16) protein of Borrelia burgdorferi is a surface-exposed antigen with a repetitive motif that confers partial protection against experimental Lyme borreliosis. Infect Immun. 2001;69:1409-19.

92. Liang FT, Jacobs MB, Philipp MT. C-terminal invariable domain of VIsE may not serve as target for protective immune response against Borrelia burgdorferi. Infect Immun. 2001;69:1337-43.

93. Marconi RT, Earnhart CG. Lyme disease vaccines. In: Samuels DS, Radolf JD, editors. Borrelia: molecular biology, host interaction and pathogenesis. Norfolk, UK: Caister Academic Press; 2010. p. 467-86.

94. Freeman Jr TC, Wimley WC. TMBB-DB: a transmembrane beta-barrel proteome database. Bioinformatics. 2012;28:2425-30.

95. Hoenger A, Pages JM, Fourel D, Engel A. The orientation of porin OmpF in the outer membrane of Escherichia coli. J Mol Biol. 1993;233:400-13.

96. Werner J, Augustus AM, Misra R. Assembly of TolC, a structurally unique and multifunctional outer membrane protein of Escherichia coli K-12. J Bacteriol. 2003;185:6540-7.

97. Robert V, Volokhina EB, Senf F, Bos MP, Gelder PV, Tommassen J. Assembly Factor Omp85 recognizes its outer membrane protein substrates by a species-specific C-terminal motif. PLoS Biol. 2006;4:e377. 
98. Sun G, Pal S, Sarcon AK, Kim S, Sugawara E, Nikaido H, Cocco MJ, Peterson EM, de la Maza LM. Structural and functional analyses of the major outer membrane protein of Chlamydia trachomatis. J Bacteriol. 2007;189:6222-35.

99. Bunikis J, Barbour AG. Access of antibody or trypsin to an integral outer membrane protein (P66) of Borrelia burgdorferi is hindered by Osp lipoproteins. Infect Immun. 1999;67:2874-83.

100. Ostberg Y, Pinne M, Benz R, Rosa P, Bergstrom S. Elimination of channelforming activity by insertional inactivation of the p13 gene in Borrelia burgdorferi. J Bacteriol. 2002;184:6811-9.

101. Pinne M, Thein M, Denker K, Benz R, Coburn J, Bergstrom S. Elimination of channel-forming activity by insertional inactivation of the p66 gene in Borrelia burgdorferi. FEMS Microbiol Lett. 2007;266:241-9.

102. Dyer A, Brown G, Stejskal L, Laity PR, Bingham RJ: The Borrelia afzelii outer membrane protein BAPKO_0422 binds human factor-H and is predicted to form a membrane-spanning beta-barrel. Biosci Rep. 2015, 35:e00240.

103. Stejskal L. Structural characterisation of outer membrane proteins from Borrelia burgdorferi sensu lato by small-angle X-ray scattering. Fields: Journal of Huddersfield student research. 2016;2(1):e22.

104. Sadziene A, Thomas DD, Barbour AG. Borrelia burgdorferi mutant lacking Osp: biological and immunological characterization. Infect Immun. 1995;63: 1573-80.

105. Barbour AG, Jasinskas A, Kayala MA, Davies DH, Steere AC, Baldi P, Felgner $\mathrm{PL}$. A genome-wide proteome array reveals a limited set of immunogens in natural infections of humans and white-footed mice with Borrelia burgdorferi. Infect Immun. 2008;76:3374-89.

106. Exner MM, Wu X, Blanco DR, Miller JN, Lovett MA. Protection elicited by native outer membrane protein Oms66 (p66) against host-adapted Borrelia burgdorferi: conformational nature of bactericidal epitopes. Infect Immun. 2000;68:2647-54

107. Ristow LC, Miller HE, Padmore LJ, Chettri R, Salzman N, Caimano MJ, Rosa PA, Coburn J. The beta b $_{3}$-integrin ligand of Borrelia burgdorferi is critical for infection of mice but not ticks. Mol Microbiol. 2012;85:1105-18.

108. Bhide MR, Escudero R, Camafeita E, Gil H, Jado I, Anda P. Complement factor $\mathrm{H}$ binding by different Lyme disease and relapsing fever Borrelia in animals and human. BMC Res Notes. 2009:2:134.

109. Lin T, Gao L, Zhang C, Odeh E, Jacobs MB, Coutte L, Chaconas G, Philipp MT, Norris SJ. Analysis of an ordered, comprehensive STM mutant library in infectious Borrelia burgdorferi: insights into the genes required for mouse infectivity. PLoS One. 2012;7:e47532.

110. Lin T, Troy EB, Hu LT, Gao L, Norris SJ. Transposon mutagenesis as an approach to improved understanding of Borrelia pathogenesis and biology. Front Cell Infect Microbiol. 2014;4:63.

111. Bagos P, Liakopoulos T, Spyropoulos I, Hamodrakas S. A Hidden Markov Model method, capable of predicting and discriminating beta-barrel outer membrane proteins. BMC Bioinformatics. 2004;5:29.

112. Kenedy MR, Vuppala SR, Siegel C, Kraiczy P, Akins DR. CspA-mediated binding of human factor $\mathrm{H}$ inhibits complement deposition and confers serum resistance in Borrelia burgdorferi. Infect Immun. 2009;77:2773-82.

113. Lenhart TR, Kenedy MR, Yang X, Pal U, Akins DR. BB0324 and BB0028 are constituents of the Borrelia burgdorferi beta-barrel assembly machine (BAM) complex. BMC Microbiol. 2012;12:60.

114. Brusca JS, Radolf JD. Isolation of integral membrane proteins by phase partitioning with Triton X-114. Methods Enzymol. 1994;228:182-93.

115. Anand A, Luthra A, Dunham-Ems S, Caimano MJ, Karanian C, Ledoyt M, Cruz AR, Salazar JC, Radolf JD. TprC/D (Tp0117/131), a trimeric, pore-forming rare outer membrane protein of Treponema pallidum, has a bipartite domain structure. J Bacteriol. 2012;194:2321-33.

116. Luthra A, Zhu G, Desrosiers DC, Eggers CH, Mulay V, Anand A, McArthur FA, Romano FB, Caimano MJ, Heuck AP, Malkowski MG, Radolf JD. The transition from closed to open conformation of Treponema pallidum outer membrane-associated lipoprotein TP0453 involves membrane sensing and integration by two amphipathic helices. J Biol Chem. 2011;286:41656-68.

117. Heuck AP, Tweten RK, Johnson AE. Assembly and topography of the prepore complex in cholesterol-dependent cytolysins. J Biol Chem. 2003 278:31218-25

\section{Submit your next manuscript to BioMed Central and we will help you at every step:}

- We accept pre-submission inquiries

- Our selector tool helps you to find the most relevant journal

- We provide round the clock customer support

- Convenient online submission

- Thorough peer review

- Inclusion in PubMed and all major indexing services

- Maximum visibility for your research

Submit your manuscript at www.biomedcentral.com/submit

) Biomed Central 